\title{
ANALYSIS OF THE EFFECT OF PROVISIONAL TIES ON THE CONSTRUCTION AND CURRENT DEFORMATION OF MALLORCA CATHEDRAL
}

\author{
Luca Pelà $^{\mathrm{a}}$, Julien Bourgeois ${ }^{\text {a }}$, Pere Roca ${ }^{\text {a }}$, Miguel Cervera ${ }^{\mathrm{a}}$, Michele \\ Chiumenti $^{\text {a }}$ \\ ${ }^{a}$ Technical University of Catalonia (UPC), Campus Norte, Jordi Girona 1-3, 08034 \\ Barcelona, Spain.
}

\begin{abstract}
This paper presents the analysis of the structure of Mallorca Cathedral taking into account the influence on structural behaviour of auxiliary iron ties used during the construction process. Recent studies (Roca et al., 2012, 2013) have presented some hypotheses about the construction process of the cathedral. The present study complements the previous results by considering the use of auxiliary ties as temporary stabilizing device during the construction. Evidence of the use of ties during the construction has been recognized after a comprehensive survey. The study of the role of such ties and the effect of their later removal are studied by a FE analysis carried out on a representative bay of the structure. The study includes a time-dependent FE analysis after the removal of the ties to assess the long-term structural behaviour. The results of the numerical analysis are compared with the deformation trends identified by means of a recent monitoring campaign.
\end{abstract}

Running Head: Use of ties in Mallorca Cathedral construction

Keywords: Masonry, Wrought iron, Creep, Damage, Long-term deformation, Geometric nonlinearity, Historical construction, Gothic, Construction process, Temporary tie rods.

\footnotetext{
* Corresponding author.

E-mail addresses: julienbourgeois5@gmail.com (Julien Bourgeois), luca.pela@upc.edu (Luca Pelà), pere.roca.fabregat@upc.edu (Pere Roca), miguel.cervera@upc.edu (Miguel Cervera), michele@,cimne.upc.edu (Michele Chiumenti).
} 


\section{Introduction}

As recognized by relevant international documents (ICOMOS/ISCARSAH 2003; ISO13822 2010), the restoration of historical buildings must be based on a detailed knowledge of their structural features, the real causes of damage and the possible historical events that may have influenced on their final condition. This detailed knowledge is useful for the design of efficient interventions which have to be at the same time respectful of the cultural value of the building. An important aspect of the necessary knowledge lays on the identification and characterization of relevant historical phenomena or events, occurred during the history of the structure, that may have influenced the later behaviour or condition. Among these, the construction process and the long-term deformation and damage, due to creep and related time-dependent phenomena, deserve special attention. The construction process, especially in the case of Gothic cathedrals and similar buildings, underwent difficult intermediate conditions during which the structure might have experienced initial deformation and even some
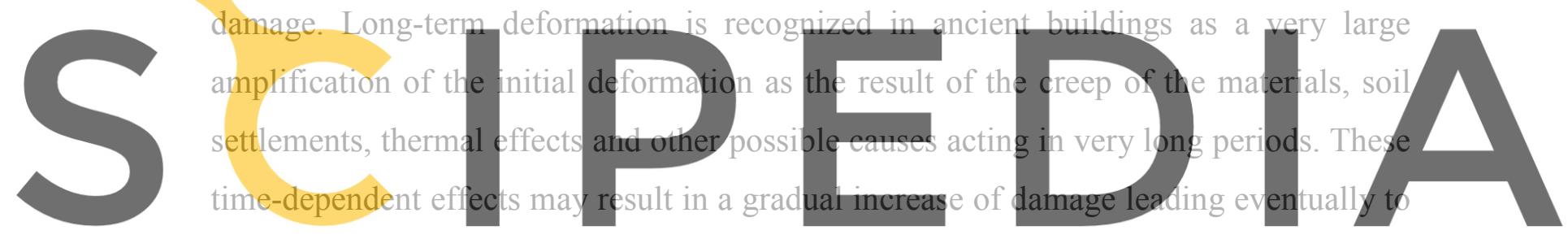
collapse (Binda et al. 2001, 2003).

Register for free at https//www.scipedia.com to download the version without the watermark Nowadays the study of historical structures is largely benefiting from the development

of advanced numerical tools (such as the FE method) including appropriate descriptions of the mechanics of ancient masonry (Roca et al. 2010). However, the application of advanced methods to the study of historical structures is still facing significant challenges. The integration in the study of the effects derived from the construction process, and those related with long-term deformation and damage are among these challenges (Saloustros et al. 2015).

The need of research on the construction process is especially applicable to buildings of the Gothic era, for which the stable equilibrium state of the structure was reached only after the completion of the overall construction. Before that, the unfinished parts of the structure usually underwent deformations which could be significant. To counterbalance these deformations, the master builders often used temporary structural devices during the construction process, such as iron ties. Moreover, the geometry of the structure was continuously corrected during the construction to account for occurring deformations 
such as those due to mortar or soil settlements. The unbalanced horizontal thrusts transmitted by the arches and vaults during intermediate construction stages, when the structure was still incomplete, might cause difficult equilibrium conditions and large deformation. Therefore, temporary devices such as iron ties were extensively used in Europe to withstand the unbalanced thrusts of the vaults in the lateral naves before the completion of the central one (Fitchen, 1961).

Mallorca Cathedral, one of the most impressive Gothic monuments of the Mediterranean area, is a perfect example of the combined consequences of both the construction process and the time-dependent phenomena in the materials, like the longterm creep behaviour of masonry. Numerous structural studies of the cathedral have been carried out since the beginning of $20^{\text {th }}$ century and until recently (Rubío, 1912; Mark, 1982; Roca, 2001). An advanced computational model has been utilized lately to analyse the structure including the effect of the construction process (Clemente, 2006; Roca et al., 2012, 2013). This first attempt to model the construction process investigated the possibility of erecting the structure without the use of auxiliary

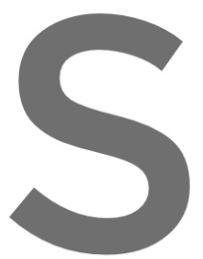
investigated the possibility of erecting the structure w
members such as iron ties. The analysis showed that with
or other auxiliary devices the structure would exnerience
deformation during the construction. out the une of tempo

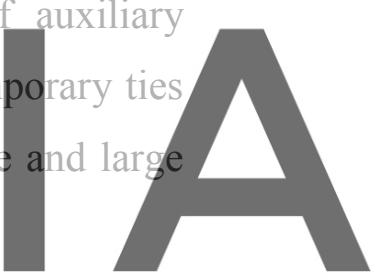

More recently, a comprehensive on-site investigation of the building has allowed the Register for free at https//www.scipedia.com to download the version without the watermark identification of the remains of iron ties used during construction (Bourgeois, 2013).

These remains consist of tie ends clamped into the masonry and left there after having cut and removed the rest of the tie. In fact, there are two intact ties still visible in the building, which were previously regarded as a latter strengthening, but might be the only left uncut during the construction. The use of ties during the construction, however, is not known to be mentioned in any available historical document on Mallorca cathedral.

This work focuses on the effect of the use of auxiliary iron ties on the construction process and current deformation of one typical bay of the cathedral. The analysis of this single macroelement is rather representative since the construction process of the whole cathedral was characterized by a sequential building of the bays from the presbytery to the façade (González et al., 2008).

It is worth noting that the present research is a further stage of a broader long term study. All the conducted studies have contributed to deepen the knowledge of the 
present condition and behaviour of a complex and unique building. The huge dimensions, the three-nave system with high-rise aisles, the spaciousness of the interior, the extreme slenderness of piers and structural members are some of the peculiar features that make Mallorca Cathedral one of the most ambitious and sophisticated examples of Gothic architecture.

The outline of the paper is as follows. Firstly, a general overview of wrought iron members used during the Gothic era is given, in order to provide useful information and to better contextualize the research. Secondly, a brief description of Mallorca Cathedral and a summary of principal outcomes from previous studies are presented. The emphasis in this paper is on the historical data available about the construction process of a single bay together with some possible hypotheses about the building technology adopted. The bay selected for the analysis is the fourth one counted from the presbytery, located close to the false transept. Then, the results of on-site investigation are detailed, including the survey and mapping of the tie remains within the cathedral. The locations of the ties as well as their dimensions and mechanical properties are defined according

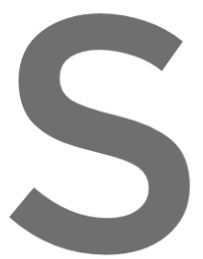
to the results of a phot model developed temporary ties durin
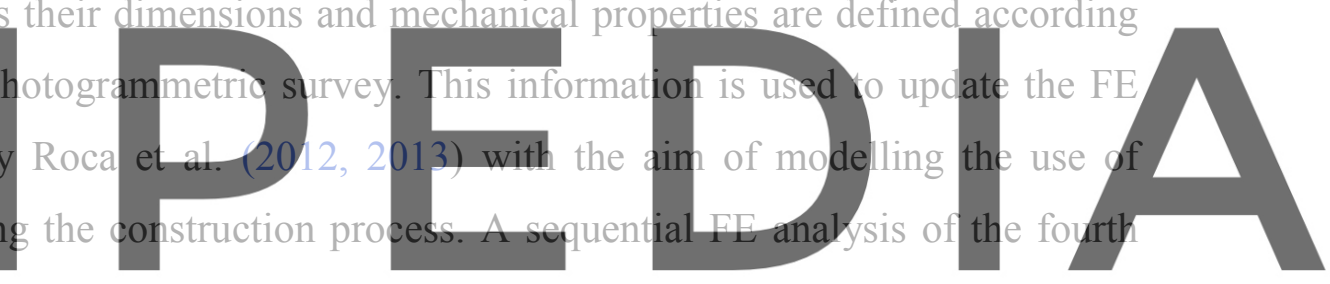

bay is carried out to understand the structural role of ties in the intermediate stages of

term effects due to the removal of ties and the creep behaviour of masonry after the completion of the bay. The conclusions of the research are aimed to provide a better understanding of the complex construction process of a Gothic cathedral and its influence on the current deformed state of the structure.

\section{Structural iron elements in Gothic construction}

The recognition that iron was largely used in Gothic construction is relatively new. Indeed many authors, architects and engineers of the $18^{\text {th }}, 19^{\text {th }}$ and $20^{\text {th }}$ centuries and even before (Delorme, 1567; Gau, 1841; Ruskin, 1849) decried the use of iron in the construction of Gothic monuments for numerous reasons. Among them, they mentioned its durability problems causing rusting and stone damage, its subjective non-aesthetic, its poor value as a construction material compared to the nobility of stone and its supposed incompatibility with traditional ways of construction. Iron was also 
considered by some authors as an "easy" way to build, a trick that should not have been used for the construction of the great Gothic monuments (Delorme, 1567).

The careful studies of Gothic architecture by Viollet-le-Duc (1854) changed significantly the understanding of the use of iron in Gothic construction. Iron was no more seen as a dangerous material but, on the contrary, as a useful one that served completely the goals of this type of construction. With the support of well-documented plans and drawings (Figure 1a) he showed the importance of iron elements as structural and non-structural devices. However, and in spite of it, he considered Gothic architecture as essentially lithic: stone was the principal structural material while iron had only a minor role. Even if some $20^{\text {th }}$ century authors recognized the use of iron in Gothic constructions (Acland, 1972), it is only at the beginning of the nineties that the research on Beauvais Cathedral carried out by Taupin (1996) plainly proved the importance of the presence of iron elements in Gothic construction and their essential structural roles. Successive researches on this subject (L'Héritier et al. 2005, 2007; Bernardi and Dillmann, 2005; Timbert and Dillmann, 2010) showed the huge quantity
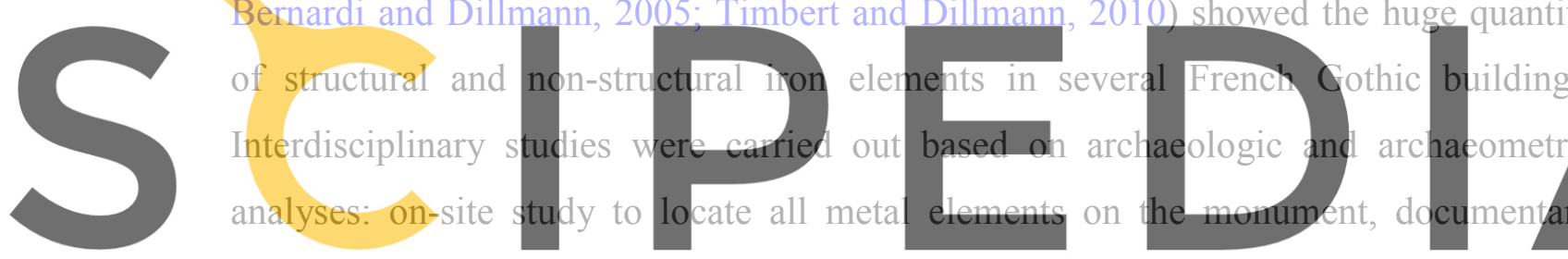

study to assemble all the mentions of metal in the construction accounts, and

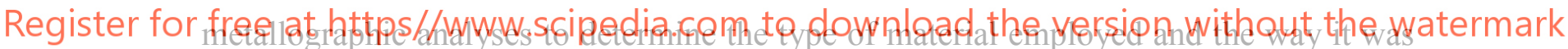

worked. Integrated methodologies based on slag inclusion analyses were used to distinguish ironmaking processes (bloomery or indirect) and to determine if artefacts have the same origin, in terms of iron ore reduction system (Dillmann and L'Héritier, 2007).

From the aforementioned researches, it was proved that iron was used both as a temporary and a as a long-lasting device, and for structural and non-structural purposes. In fact, due to its advantageous mechanical properties, it was thanks to the use of iron that Gothic architects and builders could realize their dream of space, lightness and height.

Together with other structural elements made of iron (bars in glass stained windows, clamps, studs, dowels, hooks, chaining systems), temporary and permanent ties were of primary importance for numerous Gothic structures (L'Héritier et al. 2012). A tie can be defined as "a piece of metal or wood that maintains the spacing of the truss beams of a 
wooden frame, or the tilting of two parallel walls, or the thrust of an arch" (Viollet-leDuc, 1854). These elements can be divided into two different categories.

On the one hand, temporary ties that were employed to withstand the horizontal thrust of the vaulting systems during the construction phases of a monument. In effect, a Gothic monument is supposed to be stable at the end of its construction, when the complex system of horizontal and vertical thrusts is properly balanced. Therefore, temporary devices had to be designed in order to bear the unbalanced thrusts during the intermediate stages of the construction. Together with the use of centerings that were expensive and difficult to uninstall, Gothic builders developed other temporary tools like wooden and iron ties (Brunet, 1928). The former were embedded inside the masonry and then cut after the structure had reached a sufficient stability, like in Chartres, Amiens and Soissons cathedrals. For iron ties, hooks and rings allowing the ties to be removed after the construction process were often used. Temporary ties were also used to prevent disorders after decentering during the settlement of the mortar in masonry. Nevertheless, once the construction was finished and the settlement problems

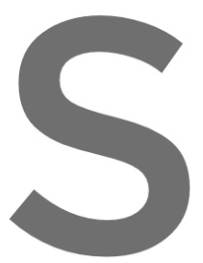
in the masonry seemed to have been stabilized, these ties apparently did not present any advantage for the st structural system made of flying arches, pinnacles (Viollet-le-Duc, 1854; Choisy, 1899). Relevant examples are tie-rods in

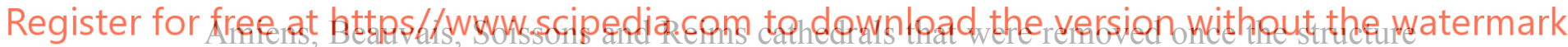
had settled after the building process.

On the other hand, permanent ties were designed to be a fully active part of the structure even after the completion of the construction. Those ties were essentially made of iron. This technique was mainly developed and used in Italy and was also often applied during consolidation works realized after the construction was completed (Guadet, 1907). The use of permanent ties saves lithic material and thus significantly reduces or even replaces the flying arches and buttresses systems. Permanent ties as a way to strengthen the structure have been also used in the exterior structure to withstand the horizontal wind forces, especially in case of slender buttresses. Beauvais Cathedral in France is an example of the use of such a technique (Dillmann, 2011).

The use of ties was widespread during medieval times in Europe. Not surprisingly, it is in France, cradle of Gothic architecture, where it is possible to observe a consequent number of Gothic monuments with remains of temporary ties. The principal nave of 
Basilica Saint Marie-Madeleine of Vezelay rebuilt during the $12^{\text {th }}$ century (Figure $1 \mathrm{~b}$ ) (Lethaby, 1906), Reims Cathedral as well as the cathedral Notre-Dame of Amiens (Figure 1c) are representative examples of the use of temporary ties. As for permanent ties, the most representative examples can be found in Italy, such as the Basilica of San Petronio in Bologna, the Cathedral of Santa Maria del Fiore in Florence and Milano Cathedral. Other examples can also be found in France, like the Cathedral SaintGervais-et-Saint-Protais (Figure 1d).

Finally, the ties have been used as later strengthening systems, when the thrust of the arches and vaults was not effectively taken by the system of flying buttresses (Brown, 1845). This problem may be due to several different reasons such as underdimensioning of masonry elements, deformation accumulation due to viscous effects, increase of loading over the arches or vaults or partial destruction of the structural system. In any case these phenomena induced some damage to the structure and ties were added to fix the problem. This is the case, for example, of Soissons Cathedral

where a complete strengthening system was added to the initial construction (Dillmann,

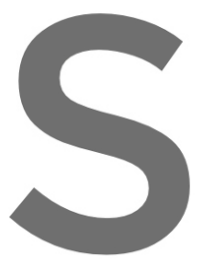
2011). Strengthening ties were added in nodern times in numeroys French historical monuments because of alarning deformations and settlements, e.g. Notre-Dame Amiens, the Great Abbey Church of Abbeville and the Choir of Saint-Julien-Le-Paurre in Paris. Also the Cathedral of Vitoria, Spain, was strengthened using rod-ties because

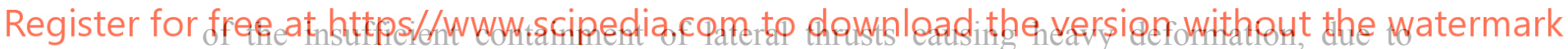
absence of flying buttresses in the original design and their inefficient late addition (Azkarate et al. 2001).

\section{Mallorca cathedral: collected data}

The cathedral of Santa Maria in Palma de Mallorca (Figure 2) is one of the most emblematic Gothic monuments of the Mediterranean area and especially of Spain. The cathedral was progressively constructed over a period of 300 years, from 1306 to 1600 . It presents typical features of the so-called Catalan Gothic Style such as high lateral naves, the presence of chapels located between massive buttresses and extremely slender octagonal piers, resulting in a spacious and diaphanous interior space. The cathedral was built with limestone from different local quarries.

The cathedral has an overall length of $121 \mathrm{~m}$ and a width of $55 \mathrm{~m}$ (Figure 3). The central nave has a length of $77 \mathrm{~m}$, the free span of the vaults is $17.8 \mathrm{~m}$ and the height from the ground to the top of the interior vaults is $44 \mathrm{~m}$. The height of lateral naves is 
$29.4 \mathrm{~m}$ and the span of their vaults is $8.75 \mathrm{~m}$. The piers have an octagonal section with circumscribed diameter of 1.6 or $1.7 \mathrm{~m}$ and a height of $22.7 \mathrm{~m}$ to the springing of the lateral vaults. There are a total of seven bays, including a false transept with lateral entrances.

Mallorca cathedral was first conceived as a single nave structure of a more moderate height. The construction began in 1300 from East with the construction of the so-called Trinity Chapel and Royal Chapel, which today form the presbytery of the cathedral. According to the most widely accepted interpretation, by 1330 it was decided to build the remaining construction according to a three-nave plan and yet, by the mid of 14th century, it was decided to increase the height of the vaults. The construction of the main nave developed during the rest of 14 th and 15 th centuries with a major interruption from 1460 to 1570. The West façade, of Renaissance style, was built from 1594 to 1601, when the cathedral was consecrated. The West façade was demolished and replaced by a new façade by mid-19th century due to a concerning out-of-plumb. More information about the history of the cathedral, the existing damage and structural

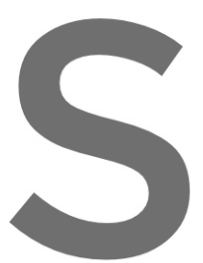
alterations can be found in previous studies
al., 2012, 2013; Bourgeois, 2013).
Several NDT and MDT techniques
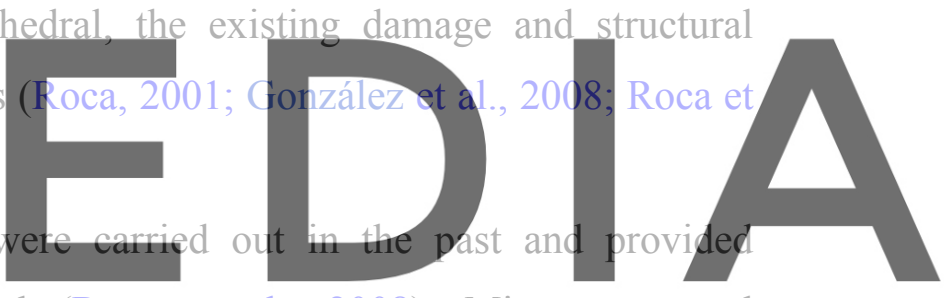

valuable information about the cathedral (Roca et al., 2008). Microscopy and

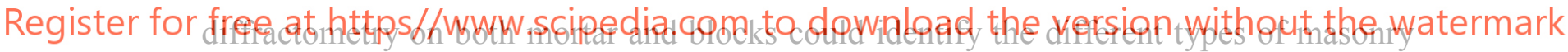

corresponding to different construction stages and confirm the hypotheses about the construction process derived from the historical research (see Section 3.1). Seismic tomography and pulse radar were carried out in order to identify the internal morphology of the structural members and the quality of the materials. An integrated near-surface geophysical survey was carried out both inside and outside the cathedral perimeter to investigate the subsoil (Pérez-Gracia et al., 2009). Continuous dynamic monitoring was considered to characterize the dynamic response of the building under low amplitude vibrations (Martínez 2007, Elyamani et al. 2012).

A five-year monitoring system was installed in the Cathedral in 2003 (Roca and González, 2008). Significant deformations were measured in the piers, which showed a certain curvature and lateral displacement, especially along the direction transverse to the nave (Roca et al., 2012, 2013). The bays lateral deformations are very variable without following a similar trend, i.e. with random deformation in piers both in terms of direction (inward or outward to the nave) and magnitude. The maximum lateral 
displacement measured in piers ranges from $0.02 \mathrm{~m}$ up to, in a single case, $0.26 \mathrm{~m}$, with an average (in absolute value) of $0.13 \mathrm{~m}$ corresponding to a ratio of $1 / 175$ with respect to the height. The piers placed between the third and fourth bay (the bays are numbered starting from the apse) showed at their top a symmetrical component of the horizontal displacement of $0.095 \mathrm{~m}$ with a cumulative rate of $0.1 \mathrm{~mm} /$ year.

\subsection{Construction process}

Even if historical data on the construction process of Mallorca Cathedral are scarce, it has been possible to find documents on the construction of its fourth bay (Roca et al., 2013) which lasted from 1391 to 1460 (Figure 4). First, the perimeter structure, including the lateral chapels, walls and buttresses were built. Then the piers were added, followed by the construction of one of the lateral vaults, the so-called Epistle vault (located towards the South), then the second one, the Gospel vault (located towards the North), and finally the vault of the main nave. The construction of each vault took around one year. Because of some interruptions in the work, the period of time between
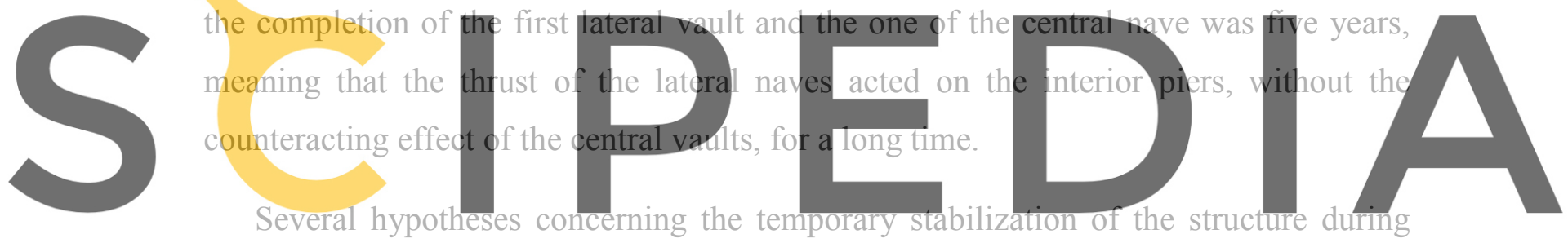

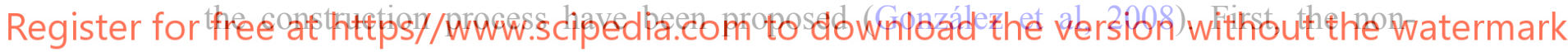
finished structure may have been able to withstand the thrust itself without any auxiliary devices, thanks to its small tensile strength. Tensile strength is usually limited in masonry structures and it is more likely to vanish in the medium or long-terms due to environmental cyclic actions or decay. Nevertheless, in the early stage of construction this small tensile strength might have been enough to overcome the lateral thrust. This possibility has been examined in depth in some previous studies (Clemente, 2006; Roca et al., 2012, 2013). A second hypothesis is that the centering used for the lateral vaults may have been active during the construction process of the bay, until the central nave was finished. Such solution would have led to difficult equilibrium conditions during the final removal of centering, causing randomly unbalanced inward or outward thrust. Finally, other types of temporary devices, such as iron or timber ties across the lateral arches or struts across the central one, may have been used to resist the thrust of the lateral vaults. The possible use of iron ties is examined in this study, since their remains can be recognized on the structure nowadays, as it will be explained in Section 3.2. 
Such solution seems more conservative and realistic than the first or second hypotheses mentioned. The iron ties, presumably installed before the construction of the aisles, can resist the thrust transmitted by the lateral vaults and limit the deformation of the pier towards the unbuilt central nave. After the completion of the central nave, the iron ties would experience a certain unloading due to the contrasting effect of the new outward thrusts coming from the central vault. For this reason it was possible to remove the ties after the completion of the central nave. In spite of the use of ties, the construction process still involved some uncertainty and risks because, even after the completion of the central vaults, the ties might retain significant forces that would be suddenly transferred to the structure when they were cut and removed.

Even if it will not be addressed in this study, another interesting problem is the longitudinal stability of the structure during the construction process. In effect, during the intermediate construction stages in the longitudinal direction, the piers had to withstand the unbalanced longitudinal thrusts of both the lateral and central vaults. The main body of the cathedral was constructed bay after bay over a long period of time and

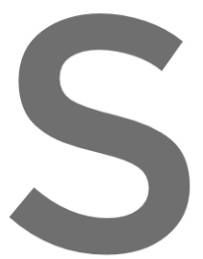
this may have led to significant deformations in the
historical information available discards the possibility of
the clerestory arches as elements stabilizing longitudina
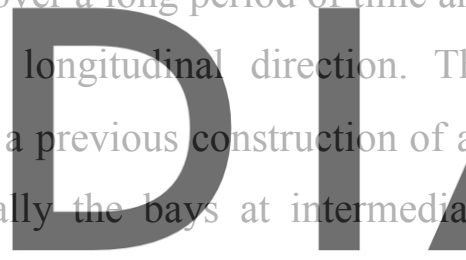

stages. Therefore, longitudinal temporary members, like iron ties and timber struts,

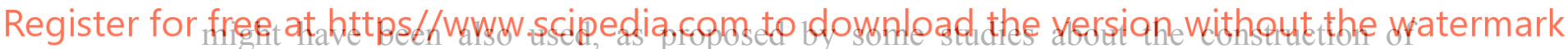
medieval cathedrals (Viollet-le-Duc 1854; Fitchen 1961).

\subsection{On-site evidence of the use of auxiliary ties in the construction process}

As it has been observed in previous studies (Clemente, 2006; Roca et al., 2012, 2013), the use of auxiliary ties during the construction process of Mallorca Cathedral cannot be disregarded. Darker spots have been detected on the surface of the masonry, in the lower part of the arches at two different heights. These spots seem to exist on each side of the lateral bay (Figure 5). Once the corresponding two spots of each side are linked together with fictive lines, a certain parallelism appears between the lines. The presence of two remaining ties for two of the bays (Figure 5a and Figure 5b) has also been noticed. There is no information on whether these remaining ties were placed during the construction or were installed later as a strengthening device. From these preliminary observations, a thorough on-site inspection has been carried out to detect 
evidences on the past use of ties in the Cathedral. The considered approach includes onsite inspection (Figures 5, 6 and 7) and photogrammetry (Figure 8).

Firstly, dark spots, corresponding of cut tie ends, have been identified in all the bays of the cathedral (Figure 6 and Figure 7). They are present in the northern lateral nave where the remaining ties are but also in the southern nave. Therefore, they appear to be a characteristic feature of the bays of the cathedral. For most of the bays, two separate spots have been detected at the base of the arches. Uncertainties still remain for the bays 1-2 and 2-3 (Figure 6 and Figure 7) and thus a more accurate investigation should be carried out at these locations to understand if the existing spots correspond to one or two ties. One can notice the consistency of the spots' height, since they always appear at similar locations. Concerning the upper spots, they are located at the same level of the two remaining ties. The photogrammetric study of the south lateral nave (Figure 8) leads to the same conclusions and thus corroborates the temporary ties hypothesis. By zooming on the spots, it is possible to observe their real shape: concerning the upper ones, some of the pictures reveal that they are in fact remaining metallic hooks (Figure 5c and Figure 5d), iron devices extensively used during medieval times. The lower spots seem to be sawn rectangular metallic elements (Figure 5e and Figure 5a). Some damage around these spots has been also observed (Figure $5 \mathrm{f}$ ). It seems that the stone at these locations was pulled off, which may be explained by the presence of ties working in tension, leading to a concentration of tensile stresses at the location of their anchorages with the masonry. Another explanation may be that the material was damaged at such locations during the removal of the iron ties. A further explanation can be damage due to the corrosion of the remaining iron.

These features seem to be a proof of the possible use of structural iron ties during the lifetime of the cathedral. Moreover, the similarities between these elements and the ones previously observed in Amiens Cathedral in France cannot be disregarded and should be considered to reinforce the hypothesis of the use of temporary ties during the construction process of Mallorca Cathedral.

The on-site combined study provides a good approximation of the height of the ties remains and a rough estimation of the section of the missing ties. In particular, it has been possible to evaluate the height of the ties of the fourth bay, whose structural analysis is reported in Section 4. Accordingly, the connection of the first set of ties with the masonry has been considered to be located at $0.40 \mathrm{~m}$ from the top of the capital of the pier to the centre of the lower tie section (i.e. at $78 \%$ of the total height of the aisle, 
the latter considered equal to 29.4 meters) whereas the connection of the second set of ties with the masonry has been considered to be located at $2.06 \mathrm{~m}$ from the top of the capital of the pier to the centre of the upper tie section (i.e. at $84 \%$ of the total height of the aisle). Those heights have been assumed in the structural analysis for both sides of the bay and the ties are assumed perfectly horizontal. In addition, their total crosssection is assumed to be equal to $25 \mathrm{~cm}^{2}$ which is in good accordance with the average value of the cross-section measured $\left(27 \mathrm{~cm}^{2}\right)$ after the photogrammetric study. It is worth mentioning that such calculated cross section is comparable to those of existing in other Gothic churches. For instance, the cross sections of the ties of Milano Cathedral range between $35 \mathrm{~cm}^{2}$ and $55 \mathrm{~cm}^{2}$ (Vasic, 2013).

\section{Structural analysis}

Some structural analyses were previously carried out for the $4^{\text {th }}$ bay of Mallorca Cathedral. The initial studies (Roca, 2001) did not take into account the construction process, the geometric nonlinearity and the long-term creep behaviour of masonry, leading to qualitative results concerning the displacements and the deformation endured by the structure. In particular, the deformations obtained by FE analysis were too small if compared with the real ones measured during the geometrical survey of the cathedral. Later studies (Clemente, 2006; Roca et al., 2012, 2013) considered a sequential FE analysis of the construction process of the bay. The analysis was divided into three stages: a first stage involving the construction of the lower part of the bay (lower part of the buttresses, lower part of the piers and the lateral vaults), a second stage involving the completion of the bay (upper-part of the buttresses and piers together with the vault of the central nave) and a third stage taking into account the long-term creep behaviour of the masonry. The deformations obtained in these studies were closer to the real ones. These analyses were carried out with no auxiliary device for the stability utilized during the first stage of the construction, and investigated if the structure would have been able to overcome the instability during the construction phases thanks to the contribution of the tensile strength of the masonry. Nevertheless, the authors of these previous works mentioned that the use of provisional devices during the construction process of the bay could not be disregarded, even if they did not study in depth such a scenario.

In this paper, a new structural analysis is presented, based on the consideration of the use of temporary iron ties during the construction of the $4^{\text {th }}$ bay. The FE model already developed by Roca et al. $(2012,2013)$ has been improved to assess the consequences of 
the use of auxiliary devices on the construction process stages as well as their influence on the deformation of the structure, taking into account the long-term creep behaviour of the masonry. The pre-post processor GID (CIMNE, 2002) and the FE software COMET (Cervera et al., 2002), both developed at the CIMNE, have been utilized for this study. These softwares have been also applied to recent studies of masonry structures (Pelà, 2009; Pelà et al., 2013).

\subsection{Model description}

The FE model of the $4^{\text {th }}$ bay developed by Roca et al. $(2012,2013)$ has been modified in this work to include the iron ties in the structure discretization. The updated model is composed by 14,689 nodes and 49,979 elements, including tetrahedral elements to represent the solid masonry members and linear two node truss elements to represent the ties. Due to the assumed geometrical symmetry, only a quarter of the bay is modelled. Appropriate boundary conditions have been considered to take into account the effect of the rest of the bay as well as the longitudinal confinement exerted by the adjacent bays.

The total cross-section of the ties, based on the photogrammetric survey, is assumed to be equal to $25 \mathrm{~cm}^{2}$, leading to a section to implement of $12.5 \mathrm{~cm}^{2}$ (only half of each tie is modelled in a quarter of the bay). The ties are considered elastic since they are made of relatively resistant and ductile iron compared to the masonry. The solid elements surrounding the nodes connecting the ends of the 2D ties are defined as elastic in order to avoid damage due to excessive concentrations of stresses and unrealistic local failures. In the real building these ends are probably linked to timber or iron anchor devices embedded in the structural members and able to distribute the forces over sufficiently large volumes of masonry. In any case, a detailed inspection of the anchoring detail would be certainly convenient.

Additional weights like pinnacles, infill and stone pyramids over the lateral vaults have not been modelled but their weight has been considered in calculations.

A small strains/large displacements formulation is considered in the FE model to take into account the geometrical non-linearity effects. The viscoelasticity model coupled with a damage model, firstly proposed by Cervera et al. $(1995,2003)$ and Faria et al. (1998), and adapted to masonry material by Roca et al. (2012, 2013), has been also utilized for the present calculations. The constitutive equation can be written as follows: 
$\boldsymbol{\sigma}=\left(1-d^{+}\right)\left(\overline{\boldsymbol{\sigma}}_{e}^{+}+\overline{\boldsymbol{\sigma}}_{v}^{+}\right)+\left(1-d^{-}\right)\left(\overline{\boldsymbol{\sigma}}_{e}^{-}+\overline{\boldsymbol{\sigma}}_{v}^{-}\right)$

where $\boldsymbol{\sigma}$ is the stress tensor and $\overline{\boldsymbol{\sigma}}$ is the effective stress tensor related to strains $\boldsymbol{\varepsilon}$ under elastic regimen. The damage level experienced by the material can be described by means of two scalar parameters, one for cracking in tension $\left(d^{-}\right)$and another for crushing in compression $\left(d^{+}\right)$. The value of the damage indexes varies between 0 for intact material and 1 for completely damaged material. The tensor $\overline{\boldsymbol{\sigma}}_{v}$ denotes the part of the effective (undamaged) stress tensor that is related to viscosity. A split of the effective stress tensor is carried out according to Cervera et al. $(1995,2003)$ and Faria et al. (1998) in order to distinguish tensile and compressive components, $\overline{\boldsymbol{\sigma}}^{+}$and $\overline{\boldsymbol{\sigma}}^{-}$, leading to:

$\overline{\boldsymbol{\sigma}}=\overline{\boldsymbol{\sigma}}^{+}+\overline{\boldsymbol{\sigma}}^{-}=\left(\overline{\boldsymbol{\sigma}}_{e}^{+}+\overline{\boldsymbol{\sigma}}_{v}^{+}\right)+\left(\overline{\boldsymbol{\sigma}}_{e}^{-}+\overline{\boldsymbol{\sigma}}_{v}^{-}\right)$

The time-dependent deformation accumulation due to creep is described by a rheological model based on the definition of two input parameters, the participation ratio $\xi$ and the retardation time $\theta$. The viscous model can be expressed by the following equation:

$\xi \mathbf{C}: \dot{\boldsymbol{\varepsilon}}=\dot{\overline{\boldsymbol{\sigma}}}_{v}+\frac{\overline{\boldsymbol{\sigma}}_{v}}{\vartheta}$

in which $\mathbf{C}$ is the isotropic linear-elastic constitutive tensor. Introducing the viscous strain $\boldsymbol{\varepsilon}_{v}$, it can be written

$\overline{\boldsymbol{\sigma}}_{v}=\xi \mathbf{C}:\left(\boldsymbol{\varepsilon}-\boldsymbol{\varepsilon}_{v}\right)$

Substituting (4) into (3), the evolution law for the viscous strain is

$\dot{\boldsymbol{\varepsilon}}_{v}=\frac{1}{\vartheta}\left(\boldsymbol{\varepsilon}-\boldsymbol{\varepsilon}_{v}\right)$

The specific role of the participation ratio $\xi$ and the retardation time $\theta$ will be discussed in Section 4.2.2. More information about the constitutive model, the input parameters and the integration of the internal variables can be found in Roca et al. $(2012,2013)$.

The material parameters that have been used in the FE, summarized in Table 1, are the same already utilized for the analyses presented in Roca et al $(2012,2013)$. Note that the tensile strength of the masonry has been taken equal to $5 \%$ of the compressive 
strength. The Young's moduli adopted for the different masonry elements have been taken from a previous study by Martínez (2007).

The properties of wrought iron have been decided using available literature for historical iron construction (Leutwiler, 1917; Whitey and Aston, 1926; DB Netz AG 2002; Schweizerische Bundesbahnen 2002; Network Rail 2001; Juhin 2005; Mechanical Engineering 2009). Reference values for Young's modulus range between $200 \mathrm{GPa}$ and $243 \mathrm{GPa}$, whereas for tensile strength range between $250 \mathrm{MPa}$ and 390 MPa. Recent studies aimed at characterizing the material of the ties of Milan Cathedral showed that wrought iron was employed for the construction. Tensile tests on 9 samples provided a Young's modulus of $205 \mathrm{GPa}$ and a tensile strength of $300 \mathrm{MPa}$ (Vasic, 2013, Guidobaldi et al. 2014).

\subsection{Sequential analysis of the construction process}

On the basis of the on-site survey described in Section 3.2, two potential locations for the ties are assumed, an upper one located at $2.06 \mathrm{~m}$ from the top of the piers capital, and a lower one located at $0.40 \mathrm{~m}$ from this reference height. Nevertheless, even if visual evidences on the existence of tie remains have been found for each bay, only suppositions can be done about their real utilization and the duration of their action on the structure. In this study, four different tie configurations are considered during the sequential analysis of the construction process: utilization of the upper tie only; utilization of the lower tie only; utilization of both the ties (upper and lower); no utilization of ties.

A sequential FE analysis similar to the one proposed by Roca et al. $(2012,2013)$ is considered to simulate the construction process of the $4^{\text {th }}$ bay. The main difference is that the analysis is divided in this work into 4 different stages. The first stage corresponds to the beginning of the construction. During this stage, only the members corresponding to the lower part of the bay are activated in the analysis: the lower part of the buttress, the pier, the lateral vault, the lower part of the clerestory wall and the ties (Figure 9a). The inclusion of one or two ties in the FE model, according to the configuration of the auxiliary system assumed, leads to a reduction of the outwards deformation of the pier, compared to the case without ties. After this stage, the FE mesh of the upper-part of the structure is corrected before its activation. Because the lower part of the structure has undergone deformations during the first stage of the analysis, the coordinates of the nodes of the upper part of the FE mesh (deactivated) have to be 
corrected in order to represent realistically the carrying on of the construction over the already deformed lower part. This method, already used by Roca et al. (2013), is based on the two following assumptions: maintenance of the direction of the vertical and horizontal lines and negligible total elongation of the line at the boundary between parts corresponding to different construction phases. The correction to be applied to the nodes of the upper part of the FE model is given by the average displacement vector of the nodes in the boundary of the two phases after the first construction stage. After this correction has been made, the second stage, corresponding to the construction of the rest of the bay, is analysed. During this stage, the bay is completed. In addition to the sets of elements previously activated, the following ones are added to the analysis: the upper buttress, the upper clerestory, the flying arches, the diaphragmatic transverse arch with its overload, the vault of the main nave and its filling (Figure 9b). Then the removal of the ties is simulated (third stage) by deactivating them and excluding them from the FE model (Figure 9c). This sudden removal, reproducing a possible cut of the ties after the completion of the bay, leads to an increase of deformations at the top of the pier. Finally, the long-term creep behaviour of the structure is considered (fourth stage). After the deactivation of the ties, time starts elapsing and the accumulation of deformation and damage under constant loading is evaluated according to the viscous and damage model assumed for masonry. The time-dependent analysis has been carried out on the case including a single tie.

\subsubsection{Construction process and ties removal}

After the first construction stage, in which only the aisle is built, the pier receives at its top the thrust transmitted by the vault. Since the central nave is not yet built, such thrust is not balanced by the thrust coming from the central vault. The magnitude of the horizontal displacement at the top of the pier reaches a maximum if no ties are present in the aisles. As expected, the presence of one or two provisional ties reduces this deformation.

As mentioned, three different FE analyses have been carried out in this work, considering respectively the presence of the upper tie, the lower tie or both ties (Bourgeois, 2013). Table 2 summarizes the values of the horizontal displacements found at the top of the pier after each stage for different ties configurations. The results are compared with those obtained by Roca et al. $(2012,2013)$ for the case without ties. 
From the comparison of different results, it is possible to make several observations concerning the influence of the use of temporary ties during the construction process.

During the first two steps, the presence of the ties reduces the horizontal displacement $u$ of the pier: the insertion of the ties within the model limits the deformations caused by the horizontal thrust of the lateral vault. Figure 10 gives the ratio $\left(u_{0}-u\right) / u_{0}$ denoting the efficiency of the restraining effect for each configuration of ties, being $u_{0}$ the horizontal displacement for the analysis with no ties. The reported values are percentages of decrease of the displacement at the pier top, for each system and constructions stage, with reference to the case without ties. As expected, the displacement decrease is maximum $(76.6 \%)$ for the case with two ties and after the second stage. Once the construction of the bay is completed, the sudden removal of the ties causes a significant increase of the horizontal displacement. Nevertheless, at the end of the third stage the horizontal displacements of the pier are still less than the ones found in the configuration with no ties, with a reduction ranging from $21.1 \%$ for the upper tie case to $28.5 \%$ for the two ties case. The evolution of the horizontal displacement at the top of the pier follows the same tendency for the three different tie configurations.

During the first stage, the ties contribute significantly to restrain the lateral drift of the pier (Table 2). However, and as should be expected from its more adequate location, the lower tie is more efficient than the upper one. As a result, the lateral displacements experienced by the pier in the cases with two ties or with only the lower one are very similar, especially after the second stage $(4 \mathrm{~mm}$ and $5 \mathrm{~mm}$ ). The displacement is significantly larger when only the upper tie is considered $(8 \mathrm{~mm})$. After the removal of the ties (third stage), the lateral displacement of the pier is very similar in the three cases (between $12 \mathrm{~mm}$ and $14 \mathrm{~mm}$ ) and only slightly smaller than the displacement experienced in the case with no ties $(17 \mathrm{~mm})$. Therefore, the ties are helpful in limiting the difficulties and deformation experienced during the first stage of the construction, but do not have a very significant influence, after their removal, on the final deformation of the structure.

According to the analysis, the tie experiences meaningful tensile stresses due to the horizontal thrust of the lateral vault. Table 3 summarizes the values of the tensile forces and stresses for different construction stages and ties configurations. The maximum tensile stress, of 97.2 MPa, appears at the first stage in the case with only lower tie. This 
stress is far smaller than the tensile strength found for iron in the literature (see Section 4.1), meaning that the ties are not likely to reach the elastic threshold of the material.

Figure 11 shows the tensile damage patterns obtained at each construction stage for the three different configurations of ties. The distribution of damage is rather similar in the three cases during the sequential analysis. The damage at the top outer part of the pier is properly prevented by the action of ties, especially in the two ties configuration. On the other hand, the upper-tie configuration leads to the minimum extent of damage within the extrados of the aisle vault.

Figure 12 and Figure 13 show a direct comparison between the tensile damage distributions, respectively after the first and third stages, in the configuration without ties and with the sole lower tie. In the case without ties, most of the damage is concentrated at the top outer part of the pier, due to the unbalanced thrust transmitted by the vault of the aisle after the first stage (Figure 13a). After the first stage, damage can be found also at the key of the vault of the aisle and under the false window. The aforementioned damage does not spread further during the construction stage. After the completion of the third stage, some damage appears in the upper flying arch and in a lower extent also in the vault of the central nave (Figure 13b).

The tensile damage at the top outer part of the pier is minor, thanks to the structural action of the ties. On the other hand, the damage within the vault of the aisle is more distributed than in the case without ties. Also, it is not symmetric and appears mainly concentrated in two zones (Figure 12b and Figure 13b). The damage in the aisle does not spread further after the second and third construction stages due to the combined effect of the ties and the construction of the central nave.

\subsubsection{Long-term creep behaviour after the removal of the ties}

As a further step towards the study of the deformational response of the structure, a time-dependent analysis has been carried out involving the simulation of the effect of long-term creep on the structure. This analysis has been carried out on the case with a single tie used per bay, in the lower position, during the construction.

The creep behaviour of masonry has been modelled by the viscoelastic model coupled with a damage model proposed by Roca et al. $(2012$, 2013) and briefly summarized in Section 4.1. Two parameters inherent to this model must be defined: the participation ratio $\xi$ and the retardation time $\theta$. The former sets the amount of material 
stiffness susceptible to creep (Equations 3,4). The latter parameter sets the rate of viscous strains (Equation 5) and influences the time scale of the analysis. The values assumed for $\xi$ and $\theta$ set the curves obtained in terms of horizontal displacement at the top of the pier versus time. Both parameters have been adjusted by comparison with the displacements measured during the monitoring programme mentioned in Section 3 that took place from September 2003 to September 2008 (Roca and González, 2008). These dates correspond respectively to the years 543 and 548 after the completion of the bay. The monitoring system measured a symmetrical component of the horizontal displacement at the top of the pier equal to $0.095 \mathrm{~m}$ and a deformation rate equal to 0.1 $\mathrm{mm} /$ year at this location for the same period of time (Roca et al. 2012).

The main purpose of the numerical analysis was to find an absolute displacement at the top of the pier close to the one measured in reality for the same period of time. In addition, a direct comparison was carried out between the deformation rate measured on site and that calculated by the model. For this purpose, a parametric analysis was necessary to set in the model the correct values of the parameters $\xi$ and $\theta$. In fact, among all the possible combinations, only one couple of values provides both the displacement and the deformation rate matching the values recorded during the monitoring period.

The numerical curves presenting the horizontal displacements at the top of the pier in function of time are given on Figure 14a, for both the case with lower tie and without tie. The structure seems to be stable after a smaller period of time for the participation ratios of 0.925 and 0.875 and becomes unstable after a longer period of time in the case of a participation ratio equal to 0.975 . Comparing the results obtained, it is observed that the bay with the lower tie undergoes less deformation during the elapsing period than the one without tie, thanks to the initial utilization of temporary tensile resistant members. This observation is true for every participation ratio considered. The percentage of reduction of displacement due to tie effect, computed for the $543-548$ years, is $6.4 \%$ for $\xi=0.975,8.4 \%$ for $\xi=0.925$ and $20.3 \%$ for $\xi=0.875$. Therefore, the use of ties has also a lasting effect and influence on the long-term deformational response of the structure. However, this effect does not change substantially the observed deformation trends and their influence on the stability of the structure.

As shown in Figure 14b, the numerical results of the FE model with lower tie match the experimental data, both in terms of horizontal displacement and deformation rate, if a 
participation ratio of 0.925 and a retardation time of $\theta=30$ years are assumed. Only a really high participation ratio, presently equal to 0.975 , leads to structure instability. In the lower tie configuration, this failure should occur around 1240 years after the completion of the structure. Nevertheless, such a high participation ratio leads for the 543 - 548 years to a horizontal displacement of $0.157 \mathrm{~m}$ and to a deformation rate of $0.35 \mathrm{~mm} /$ year, which are in complete disagreement with the data collected on-site. Therefore this scenario should be disregarded. As for a lower participation ratio of 0.875 , even if the structure is found stable after 1000 years (the horizontal displacement is constant and equal to $0.08 \mathrm{~m}$ from this year), the computed horizontal displacement for the $543-548$ years is $0.064 \mathrm{~m}$ and the deformation rate is $0.05 \mathrm{~mm} /$ year, which are too low compared to the ones obtained from the monitoring. On the other hand, an almost perfect matching between the monitored data and the numerical analysis results is obtained for a participation ratio of 0.925 . In that case, the horizontal displacement at the top of the pier tends to be stabilized after a rather long period of time. In effect it still increases 1500 years after the completion of the bay for which it reaches the value of about $0.175 \mathrm{~m}$.

It is worth noting that the parameters of the model describing the time dependent behaviour, i.e. the participation ratio $\xi$ and the retardation time $\theta$, are of great importance for FE numerical simulations and must be carefully implemented. The viscous model adopted is sufficiently simple since it requires the calibration of only two parameters to fully describe the creep behaviour of the material. This feature of the model makes it suitable especially for practical applications. In this study, as well as in the previous studies by Roca et al. $(2012,2013)$, the participation ratio and the retardation time were estimated on the basis of the available five year-monitoring data. However, a long-term monitoring activity of the cathedral may provide more accurate data to further improve the description of the time-dependent response.

Finally, Figure 15 shows the deformed shape and the tensile damage contour at the end of the time-dependent analysis with geometric nonlinearity for a participation factor of 0.925. The tie is not visible in the figure since it has been deactivated after the third stage of the sequential analysis. The damage is mainly concentrated in the aisle vault, under the false window, at the anchorages of the already removed ties, in the flying arch and diaphragmatic arch. It can be noticed the negligible amount of damage at the top of the pier. Compared to the condition experienced after construction, additional damage appears mainly in the lateral vault. 


\section{Conclusions}

The present work has investigated the role of iron ties used as auxiliary devices during the construction of Gothic cathedrals. The study has been carried out by analysing the structural effect of ties used in the construction of Mallorca cathedral and their possible long-term influence on the deformational response of the building.

A recent inspection in Mallorca cathedral has allowed the identification of the remains of iron ties utilized during the construction and later removed from the structure. The remains consist of tie ends embedded within the masonry and left there after the cutting and removal of the ties. The ties were used to overcome the difficult equilibrium condition experienced during an intermediate construction of each bay, when the lateral vaults were already built but not yet the central one.

A FE sequential analysis has been carried out to simulate the construction process, taking into account the use and later removal of the ties. The analysis has been performed by means of a numerical model combining material non-linearity, though a continuum damage model, with geometrical nonlinearity. The analysis has allowed the quantification of the effect of the ties, which are effective in balancing the thrust of the lateral vault and restraining the lateral drift experienced by the pillars. However, the lateral drift of the piers is still appreciable due to the elongation experienced by the ties. The use of ties modifies in a significant way the distribution of initial damage in the structure.

A time-dependent analysis, based on a viscoelasticity model coupled with damage, has been carried out to study the increase of the deformation in the long-term. The parameters of the viscoelasticity model have been adjusted based on the results of a recent monitoring programme. It has been observed that the use of temporary ties during the construction has a lasting effect as a measurable reduction of the long-term lateral displacements experienced by the piers. The use of ties during the construction process also allows a significant modification of the crack pattern in the piers and vaults. Due to the tie, cracking almost disappeared in the pier but increased significantly in the arches and vaults.

\section{Acknowledgments}

This research has received the financial support from the Ministerio de Educación y Ciencia of the Spanish Government and the ERDF (European Regional Development 
Fund) through the research project MICROPAR (Identification of mechanical and strength parameters of structural masonry by experimental methods and numerical micro-modelling, ref num. BIA2012-32234).

\section{References}

Acland, James H. 1972. Medieval structure: the gothic vault. Toronto: University of Toronto Press.

Azkarate, A., Cámara, L., Lasagabaster, J. I., Latorre, P. 2001. El Plan Director para la restauración de la Catedral de Santa María de Vitoria-Gasteiz (in Spanish). In I Congreso Europeo de Restauración de Catedrales Góticas, 561-596, Diputación Foral de Álava, Vitoria-Gasteiz, Spain.

Bernardi, P., and P. Dillmann, 2005. Stone skeleton or iron skeleton? The provision and use of metal in the construction of the Papal Palace at Avignon in the $14^{\text {th }}$ century. De Re Metallica. The uses of metal in the Middle Ages. London: Ashgate, 297-315.

Bourgeois, J. 2013. Simulation of the effect of auxiliary ties used in the construction of Mallorca Cathedral. SAHC master thesis. Technical University of Catalonia, Barcelona, Spain.

Binda, L., Saisi, A., Messina, S. and Tringali, S. 2001. Mechanical Damage Due to Long Term Behaviour of Multiple Leaf Pillars in Sicilian Churches. In Proceedings of III Int. Seminar: Historical Constructions 2001. Possibilities of Numerical and Experimental Techniques, eds. Lourenço P., Roca P., 707-718, Guimarães, Portugal.

Binda L., Anzani A. and Saisi A. 2003. Failure Due to Long Term Behaviour of Heavy Structures: the Pavia Civic Tower and the Noto Cathedral. In Proocedings of 8th Int. Conf. on STREMAH 2003, Struct. Studies Repairs and Maintenance of Heritage Architecture, 99-108, Halkidiki, Greece.

Brown, Richard. 1845. Sacred architecture: its rise, progress, and present state. London: Fisher, Son \& Co.

Brunet, E. 1928. La restauration de la cathédrale de Soissons. Bulletin monumental, 57:65-99.

Cervera, M., Oliver, J. and Faria, R. 1995. Seismic evaluation of concrete dams via continuum damage models, Earthquake Eng Struct D: 24, 9:1225-45.

Cervera, M. 2003. Viscoelasticity and rate-dependent continuum damage models. Monography: 79. Barcelona: CIMNE, Technical University of Catalonia, Barcelona, Spain. 
Cervera, M., Agelet de Saracibar, C. and Chiumenti, M. 2002. COMET: COupled MEchanical and thermal analysis - data input manual version 5.0, Technical report IT-308, CIMNE, Technical University of Catalonia, Barcelona, Spain.

Choisy, A. 1899. Histoire de l'architecture. Paris: Gauthier-Villars, Imprimeur-Libraire, 2: 316337.

Clemente, R. 2006. Análisis estructural de edificios históricos mediante modelos localizados de fisuración. Ph.D. thesis. Technical University of Catalonia, Barcelona, Spain.

DB Netz AG, 2002. Ril 805: Tragsicherheit bestehender Brückenbauwerke. Germany.

Dillmann, P. and L'Héritier, M. 2007. Slag Inclusion Analyses for Studying Ferrous Alloys Employed in French Medieval Buildings: Supply of Materials and Diffusion of Smelting Processes. Journal of Archaeological Science, 34:1810-23.

Dillmann, P. 2011. From Soissons to Beauvais: the use of iron in some French cathedrals. In The Archaeometallurgy of Iron e Recent Developments in Archaeological and Scientific Research, eds. Hosek J., Cleere, Henry, Mihok L., 173-196, Prague, Czech Republic.

Delorme, P. 1567. Premier tome de l'architecture. Paris : F. Morel.

Elyamani, A., Caselles, J.O., Clapes, J. and Roca, P. 2012. Assessment of Dynamic Behavior of Mallorca Cathedral. In Structural Analysis of Historical Constructions. Proceedings of the International Conference on Structural Analysis of Historical Constructions, SAHC 2012, ed. Jasieńko J., 2376-2384, Wroclaw, Poland.

Faria, R., Oliver, J. and Cervera, M. 1998. A strain-based plastic viscous-damage model for massive concrete structures. Int J Solids Struct, 35:1533-58.

Fitchen, John. 1961. The construction of Gothic cathedrals; a study of medieval vault erection. Oxford: Clarendon Press.

Gau, M. 1841. De l'emploi du fer comme moyen de consolidation dans les monuments historiques. In Revue générale de l'architecture et des travaux publiques, 2:21.

GID: the personal pre and post-processor. 2002. CIMNE, Technical University of Catalonia, Barcelona, Spain.

González, R., Caballé, F., Domengue, J., Vendrell, M., Giráldez, P., Roca, P. and González, J.L. 2008. Construction process, damage and structural analysis - Two case studies. In Structural Analysis of Historic Construction: Preserving Safety and Significance. Proceedings of the VI International Conference on Structural Analysis of Historic Construction, SAHC08, eds. D’Ayala D., Fodde E., 643-651, Bath, United Kingdom. 
Guadet, J. 1909. Les éléments de la composition dans les édifices d'usage public. In Eléments et théories de l'architecture. Paris: Librairie de la construction moderne.

Guidobaldi, M., Vasic, M., Gentile, C. and Poggi, C. 2014. Frequency splitting in the tie-rods of the Cathedral of Milan. In Proceedings of the 9th International Conference on Structural Dynamics EURODYN 2014, eds. Cunha A., Caetano E., Ribiero P., Müller G., 1477-1483, Porto, Portugal.

ISCARSAH Committee, ICOMOS. 2003. Recommendations for the Analysis, Conservation and Structural Restoration of Architectural Heritage.

ISO/TC98. ISO/FDIS 13822. 2010. Bases for design of structures - assessment of existing structures. Genève.

Juhin, A. 2005. Structure métallographique et comportement mécanique des tirants de fer du donjon du château de Vincennes. Master thesis. Universities of Paris 6 Pierre et Marie Curie and Paris-Sud 11, Paris, France.

L'Héritier, M., Juhin, A., Dillmann, P., Aranda, R. and Benoit, P. 2005. Utilisation des alliages ferreux dans la construction monumentale du Moyen Age. Etat des lieux de l'avancée des études métallographiques et archéométriques. ArchéoSciences, 29:117-132.

L'Heritier, M. 2007a. L'utilisation du fer dans l'architecture gothique: les cas de Troyes et de Rouen. Ph.D. thesis. Université Panthéon-Sorbonne - Paris I, Paris, France.

L'Heritier ,M., Dillmann, P., Timbert, A. and Bernardi, P. 2012. The Role of Iron Armatures in Gothic Constructions: Reinforcement, Consolidation or Commissioner's Choice. In Proceedings of the 4th International Congress on Construction History, 557-564, Paris, France.

Lethaby, W. R. 1906. Westminster Abbey \& the Kings' Craftsmen: a study of mediceval building. London: Duckworth \& Co.

Leutwiler, O. A. 1917. Elements of machine design. New York: McGraw-Hill Book Company, inc.

Mark, R. 1984. Experiments in Gothic Cathedrals. Cambridge: MIT Press.

Martínez, G. 2007. Vulnerabilidad sismica para edificios históricos de obra de fábrica de mediana y gran luz. Ph.D. thesis. Technical University of Catalonia, Barcelona, Spain.

Mechanical Engineering. 2009. LAXMI Publications (P) L/TD.

Network Rail. 2001. RT/CE/C/025. Railtrack Line Code of Practice: The Structural Assessment of Underbridges. United Kingdom: Railtrack. 
Pelà, L. 2009. Continuum Damage Model for Nonlinear Analysis of Masonry Structures. Ph.D. thesis. Technical University of Catalonia, Spain, University of Ferrara, Italy.

Pelà, L., Cervera, M. and Roca, P. 2013. An orthotropic damage model for the analysis of masonry structures. Constr Build Mater, 41:957-967.

Pérez-Gracia, V., Caselles, J.O., Clapés, J., Osorio, R., Martínez, G. and Canas, J.A. 2009. Integrated near-surface geophysical survey of the Cathedral of Mallorca. Journal of Archaeological Science, 36:1289-1299.

Roca, P. 2001. Studies on the structure of Gothic Cathedrals. In Historical Constructions 2001. Possibilities of numerical and experimental techniques. Proceedings of the 3rd International Seminar, eds Lourenço P.B., Roca P., 71-90, Guimarães, Portugal.

Roca, P. and González, J.L. 2008. Estudio, diagnóstico y peritación y en su caso planteamiento de actuaciones sobre el comportamiento constructivo-estructural de la catedral de Santa María, en la ciudad de Palma, isla de Mallorca (Baleares). Fase segunda (in Spanish). Barcelona: Technical University of Catalonia.

Roca, P., Clapés, J., Caselles, O., Vendrell, M., Giráldez, P. and Sánchez-Beitia, S. 2008. Contribution of inspection techniques to the assessment of historical structures. In Proceedings of the International RILEM SACoMaTiS Conference, Varenna, Italy.

Roca, P., Cervera, M., Gariup, G. and Pelà, L. 2010. Structural Analysis of Masonry Historical Constructions. Classical and Advanced Approaches. Arch Comput Method Eng, 17:299-325.

Roca, P., Cervera, M., Pelà L., Clemente, R. and Chiumenti, M. 2012. Viscoelasticity and Damage Model for Creep Behavior of Historical Masonry Structures. The Open Civil Engineering Journal; 6 (Suppl 1-M7):188-199.

Roca, P., Cervera, M., Pelà, L., Clemente, R. and Chiumenti, M. 2013. Continuum FE models for the analysis of Mallorca Cathedral. Engineering Structures, 46:653-670.

Rubió, J. 1912. Conferencia acerca de los conceptos orgánicos, mecánicos y constructivos de la catedral de Mallorca. Barcelona: Anuario de la Asociación de Arquitectos de Cataluña.

Ruskin, J. 1849. The seven lamps of architecture. London: The Waverley Book Company.

Saloustros, S., Pelà, L., Roca, P. and Portal, J. 2015. Numerical analysis of structural damage in the church of the Poblet monastery. Engineering Failure Analysis, doi: 10.1016/j.engfailanal.2014.10.015.

Schweizerische Bundesbahnen, 2002. SBB Weisung I-AM 08/02. Bern: Baudirektion.

Taupin, J.-L. 1996. Le fer dans les cathédrales. Monumental, 13:18-27. 
Timbert, A., and Dillmann, P. 2010. Le squelette de fer des cathédrales gothiques. Paris: Cité des Sciences.

Vasic, M., Coronelli, D., and Poggi, C. 2013. A Multidisciplinary approach for the assessment of great historical structures: ties of "Duomo di Milano". In Proceedings of International Conference Built Heritage 2013, Milan, Italy.

Viollet-Le-Duc, E. 1854. Dictionnaire Raisonné de l'Architecture Française du XI au XVI siècle. Paris B. Rance Editeur.

Whitey, M.O., and Aston, J. 1926. Johnson's Materials of Construction. Hoboken: John Wiley $\&$ Sons.

\section{Tables Captions}

Table 1 Materials properties implemented in the FE model.

Table 2 Horizontal displacements at the top of the pier after each stage of the FE simulation of the construction process for different ties configurations.

Table 3 Tensile forces and stresses after each stage of the FE simulation of the construction process for different ties configurations.

\section{Figures Captions}

Figure 1 Examples of ties used during the construction process of numerous medieval monuments: Connection of a typical iron hook with the rest of the structure (a), Basilica Sainte Marie-Madeleine of Vezelay (b), Cathedral Notre-Dame of Amiens (c), Cathedral Saint-Gervais-et-Saint-Protais of Soissons (d). Sources: (a) Viollet-le-Duc (1854), (b) Timbert and Dillmann (2010), (c) commons.wikimedia.org and (d) Timbert and Dillmann (2010).

Figure 2 Mallorca Cathedral: external view (a) and view from the interior (b).

Figure 3 Transversal (a) and longitudinal (b) sections of Mallorca Cathedral.

Figure 4 Construction stages of the fourth bay (Roca et al. 2013).

Figure 5 Visual evidences of the remains of temporary iron ties for different locations: northern aisle, bay 6-7, exterior side (a); the two remaining ties in the bays 5-6 and 6-7 of the northern aisle (b); iron hook, southern aisle, bay 4-5, exterior side (c and d); northern aisle, bay 7-8, exterior side (e); northern aisle, bay 4-5, exterior side (f).

Figure 6 Mapping of the ties remains in the aisles: exterior side.

Figure 7 Mapping of the ties remains in the aisles: interior side.

Figure 8 AutoCAD section of the south nave based on the photogrammetric survey. 
Figure 9 FE analysis of the construction process: a) first stage (construction of the aisle), b) second stage (completion of the bay) and c) third stage (removal of ties).

Figure $10 \mathrm{FE}$ simulation of the construction process: ratio $\left(u_{0}-u\right) / u_{0}$ expressing the restrain effectiveness at each stage for different ties configurations.

Figure 11 FE simulation of the construction process: tensile damage contour at each stage for the three different ties configurations.

Figure 12 FE simulation of the construction process: comparison of the tensile damage contour and the deformed shape (x100) at the end of the first stage for the configuration without tie (a) and for the lower-tie configuration (b).

Figure 13 FE simulation of the construction process: comparison of the tensile damage contour at the end of the third stage for the configuration without tie (a) and for the lower-tie configuration (b).

Figure 14 FE simulation of long-term deformation: horizontal displacements increase at the top of the pier due to creep for a lower tie configuration and a configuration without tie (a), zoom of the curves on the neighbourhood of the monitoring period for the lower tie configuration (b).

Figure 15 - FE simulation of long-term deformation in the 4th bay with a lower tie: deformed shape (x20) with horizontal displacement contour (left) and tensile damage (right) for $\xi=0.925$. 


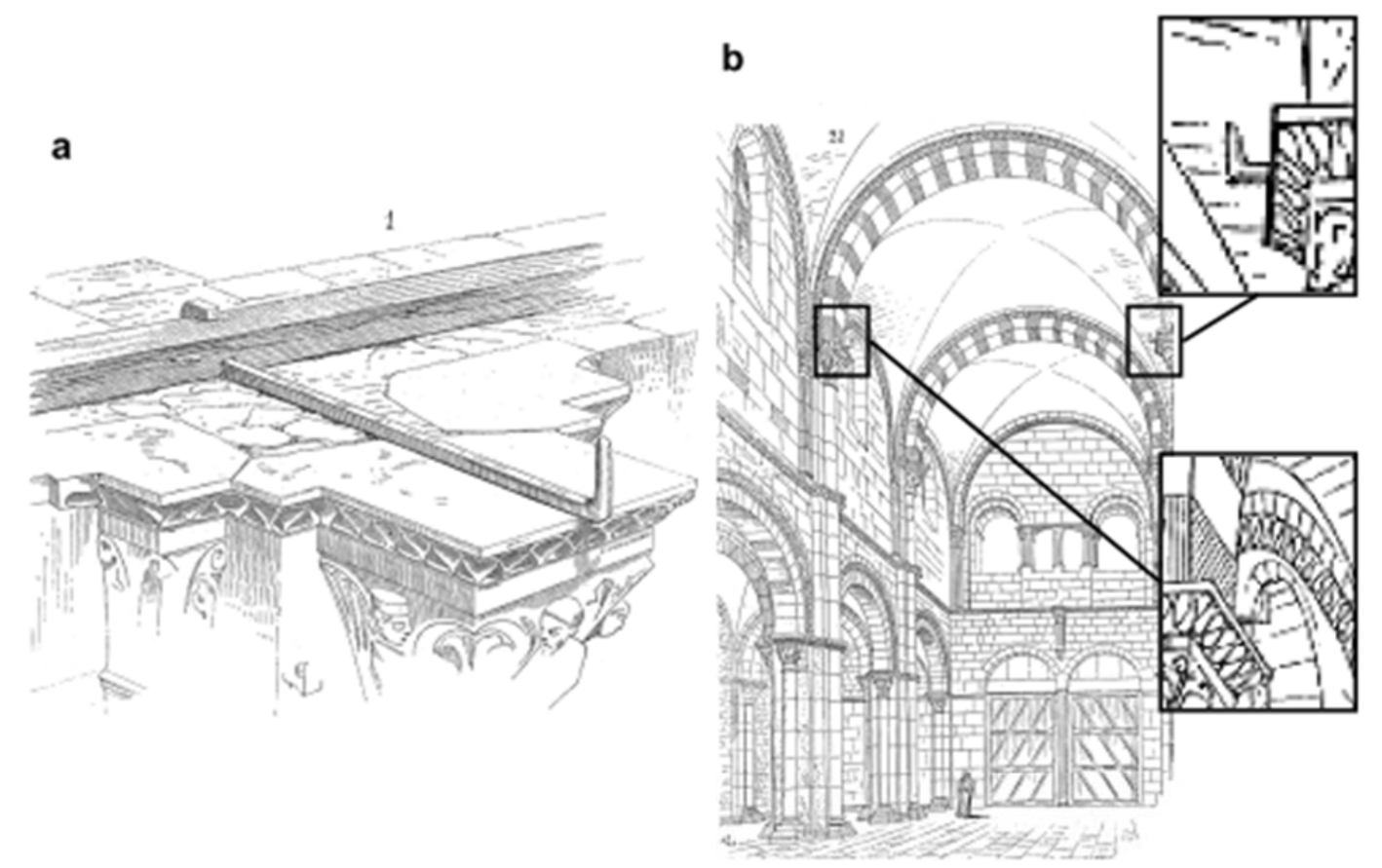

c

d
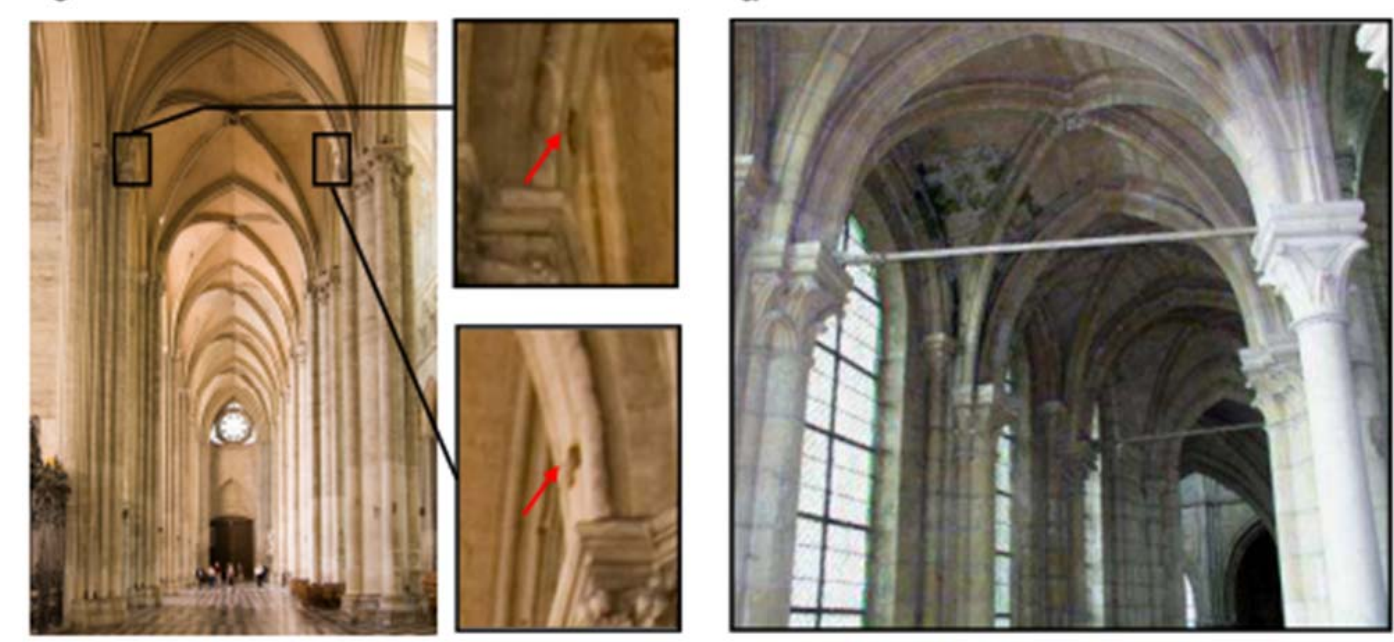

Figure 1 - Examples of ties used during the construction process of numerous medieval monuments: Connection of a typical iron hook with the rest of the structure (a), Basilica Sainte Marie-Madeleine of Vezelay (b), Cathedral Notre-Dame of Amiens (c), Cathedral Saint-Gervais-et-Saint-Protais of Soissons (d). Sources: (a) Viollet-le-Duc (1854), (b) Timbert and Dillmann (2010), (c) commons.wikimedia.org and (d) Timbert and Dillmann (2010). 

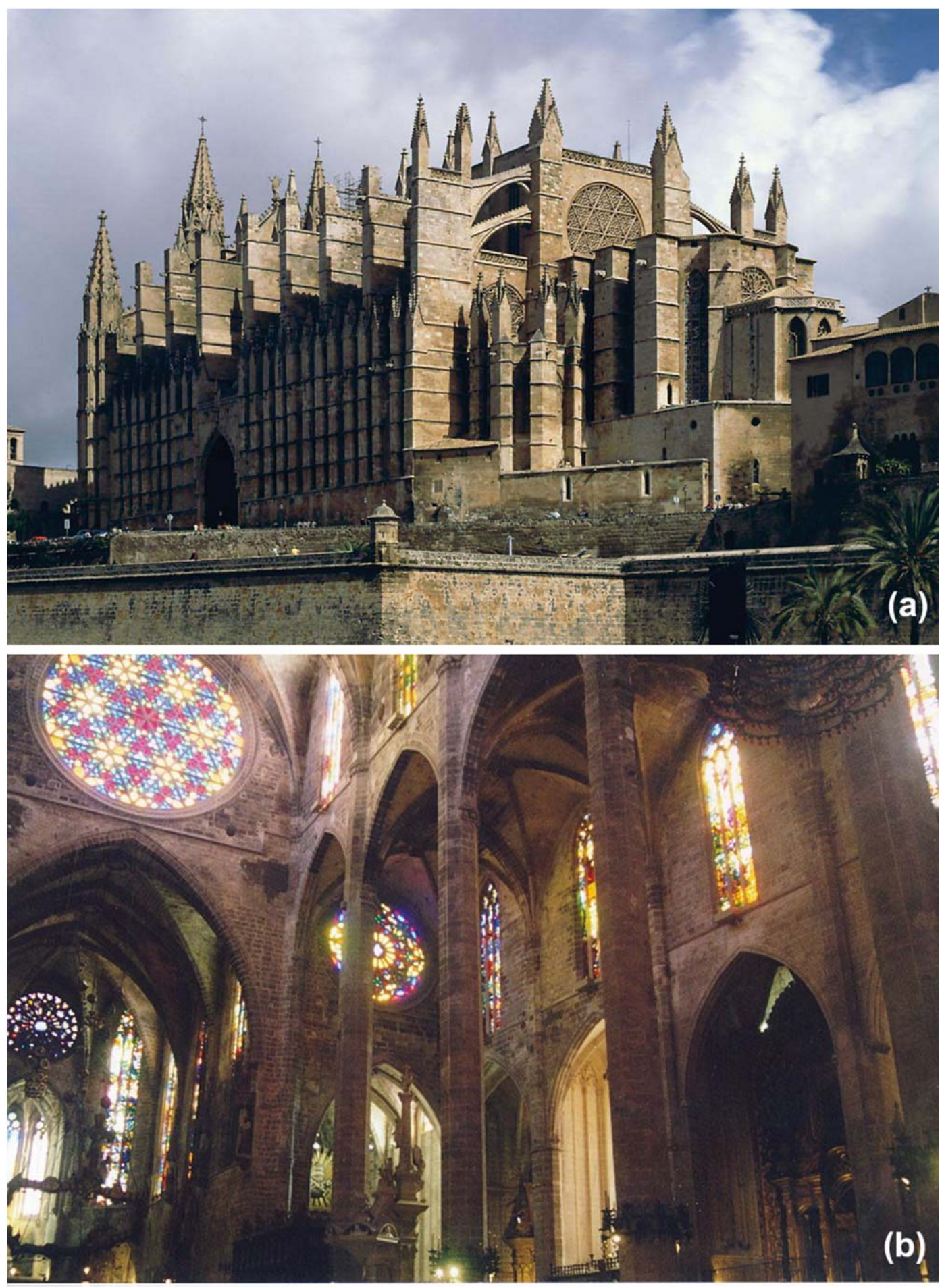

Figure 2 - Mallorca Cathedral: external view (a) and view from the interior (b). 


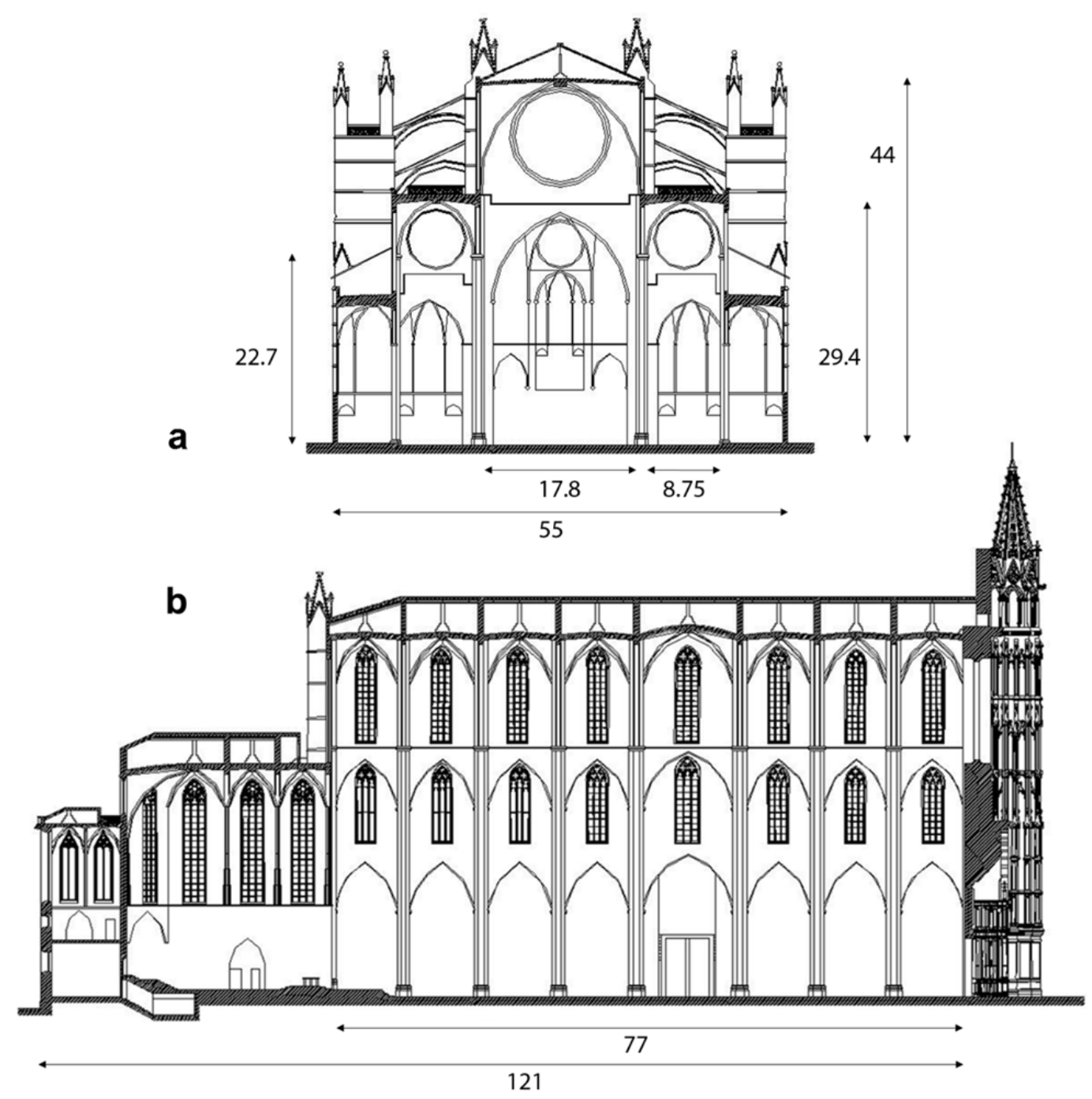

Figure 3 - Transversal (a) and longitudinal (b) sections of Mallorca Cathedral. 


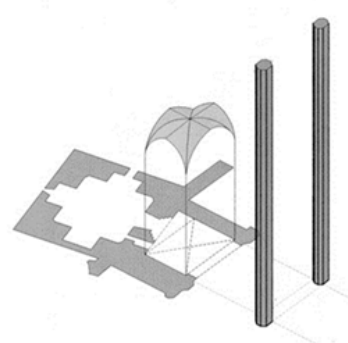

St Bernard and

St Catherine Chapels (1391-1406),

piers (1406-1426)

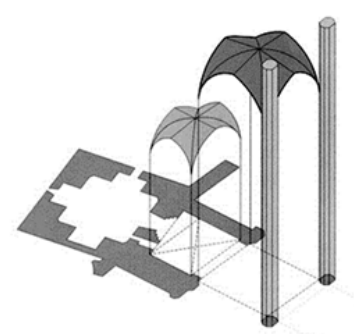

Gospel vault (1458)
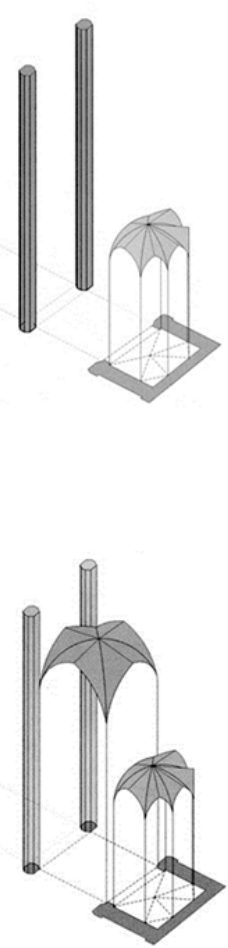
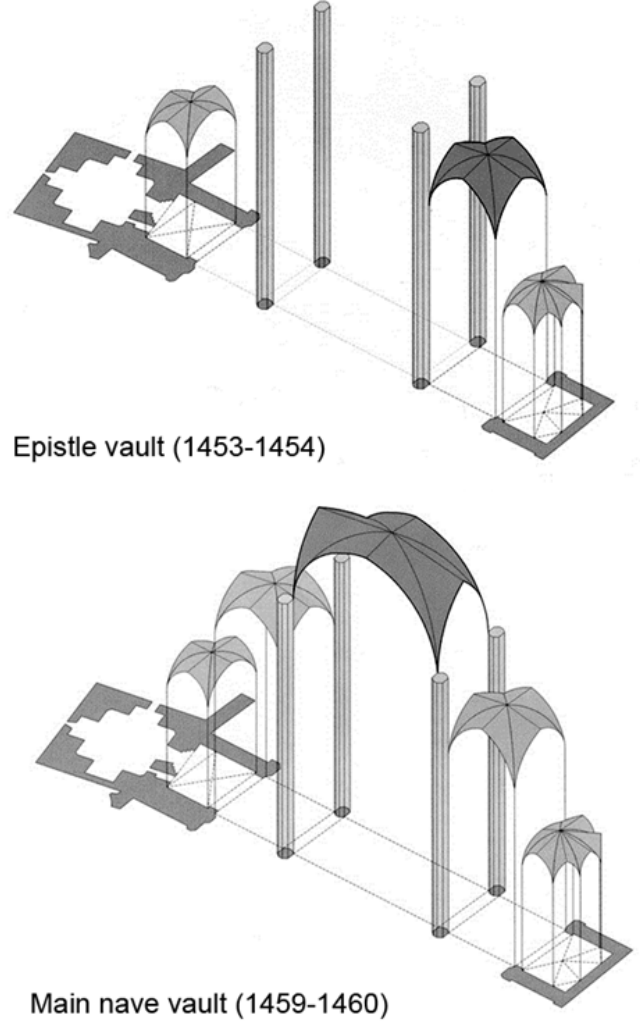

Figure 4 - Construction stages of the fourth bay (Roca et al. 2013). 

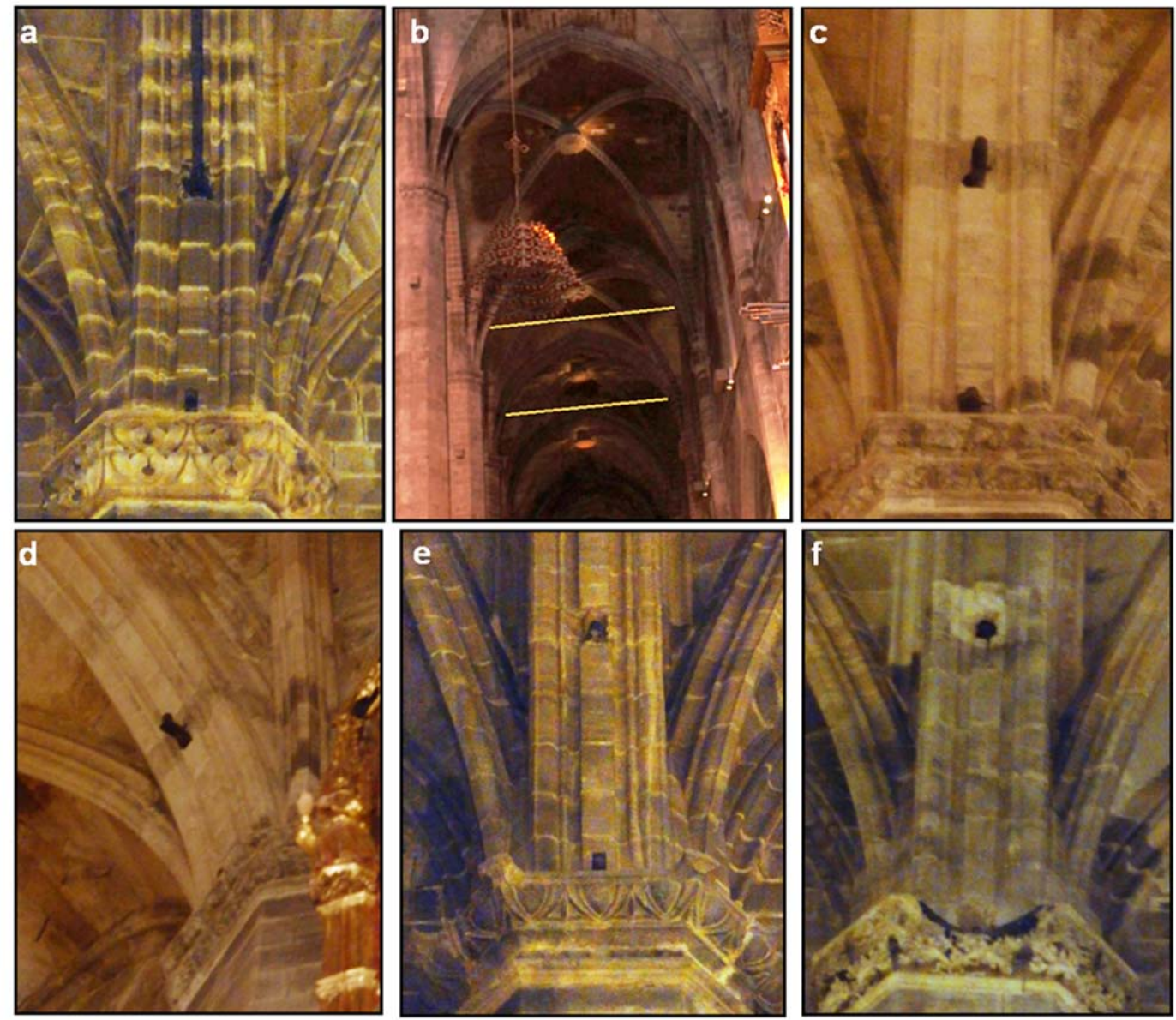

Figure 5 - Visual evidences of the remains of temporary iron ties for different locations: northern aisle, bay 6-7, exterior side (a); the two remaining ties in the bays 5-6 and 6-7 of the northern aisle (b); iron hook, southern aisle, bay 4-5, exterior side (c and d); northern aisle, bay 7-8, exterior side (e); northern aisle, bay 4-5, exterior side (f). 


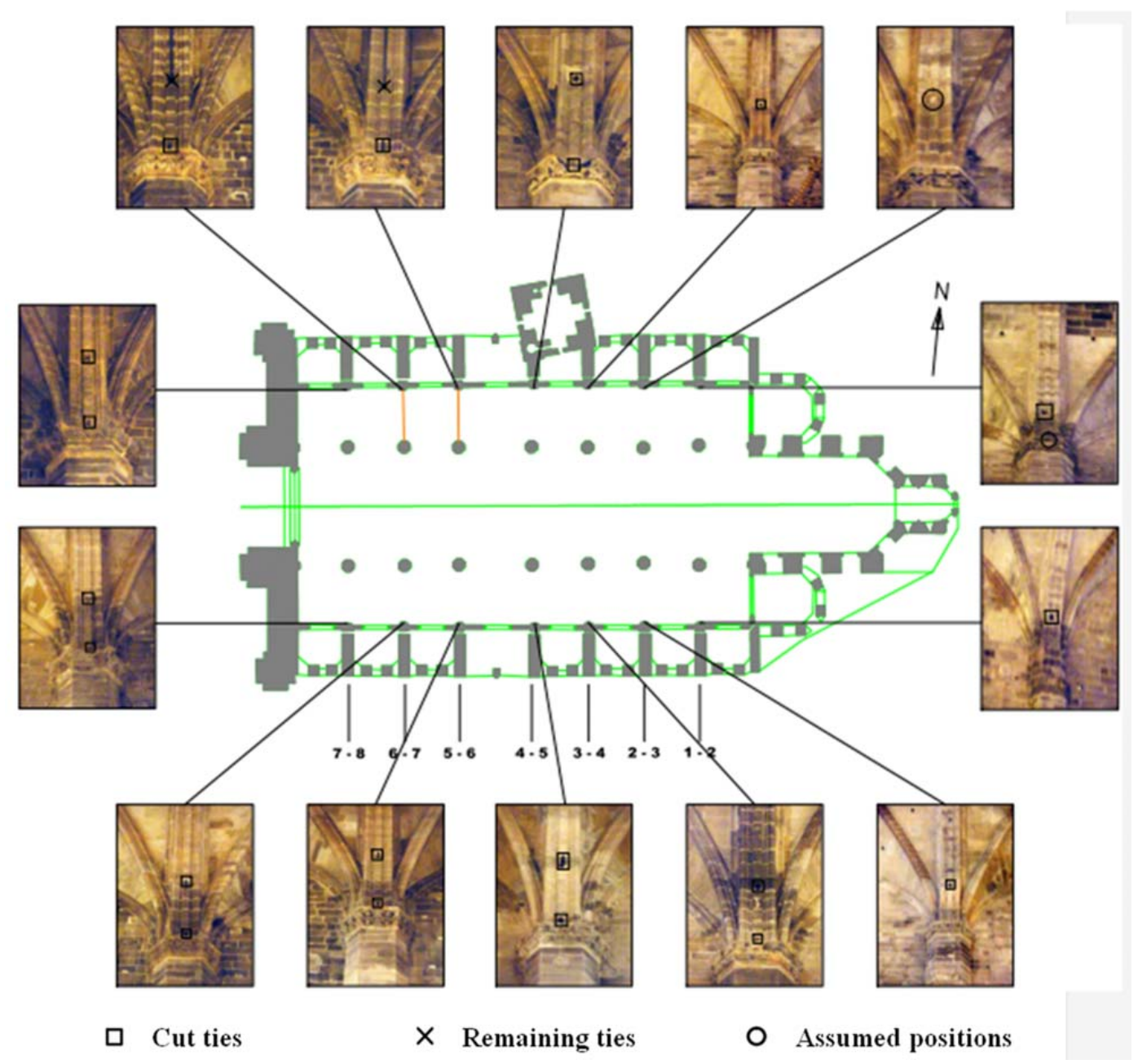

Figure 6 - Mapping of the ties remains in the aisles: exterior side. 


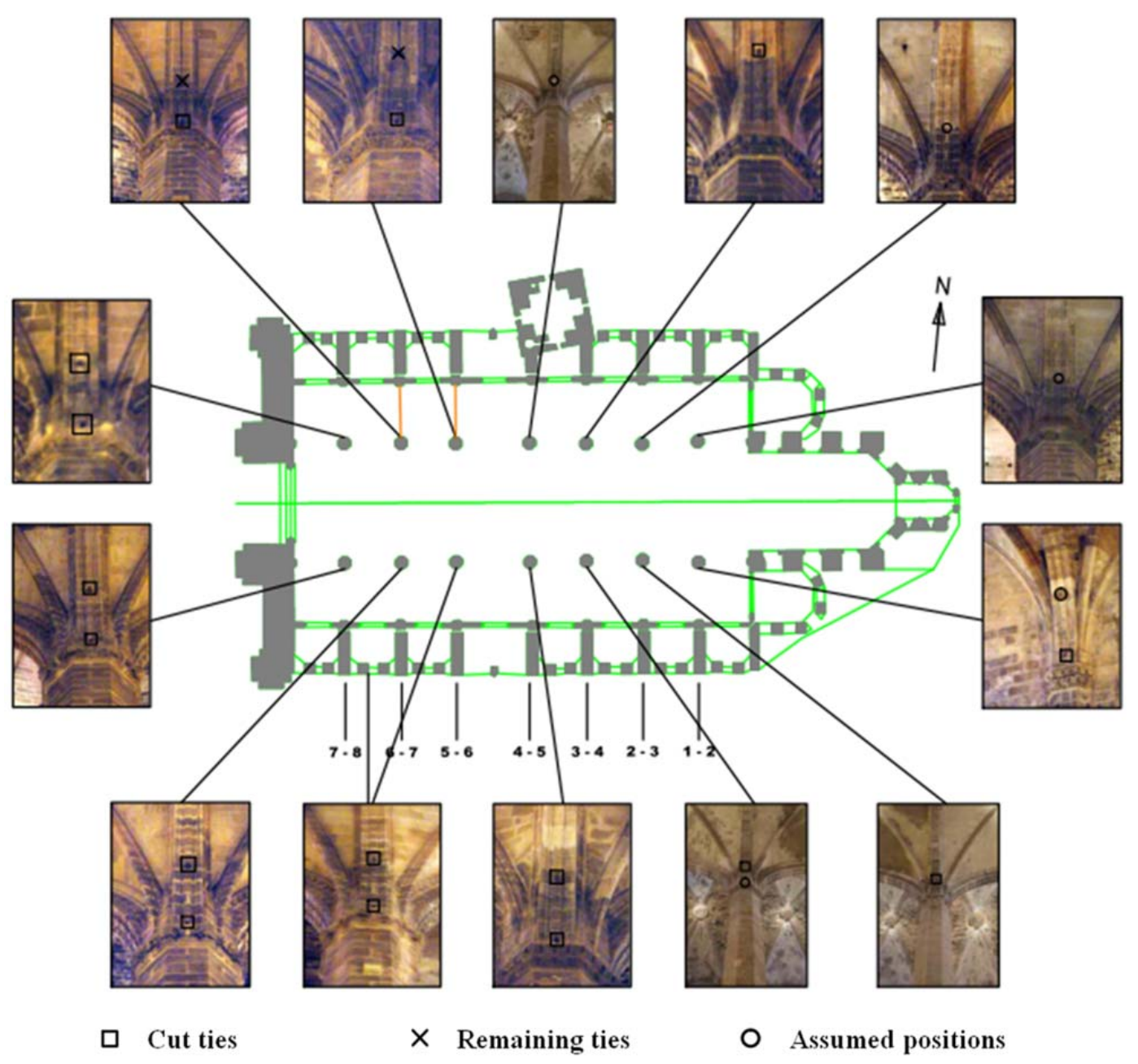

Figure 7 - Mapping of the ties remains in the aisles: interior side. 


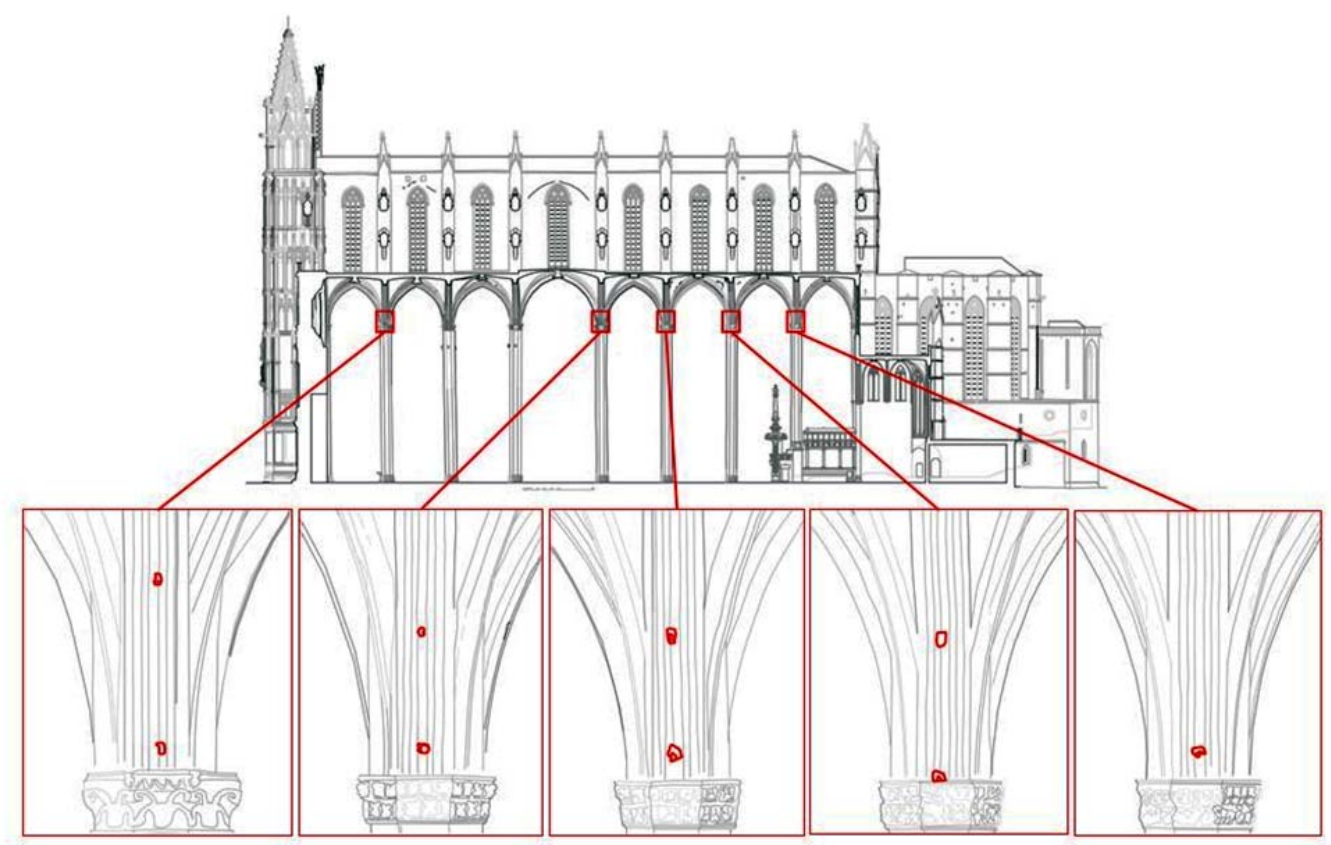

Figure 8-AutoCAD section of the south nave based on the photogrammetric survey.
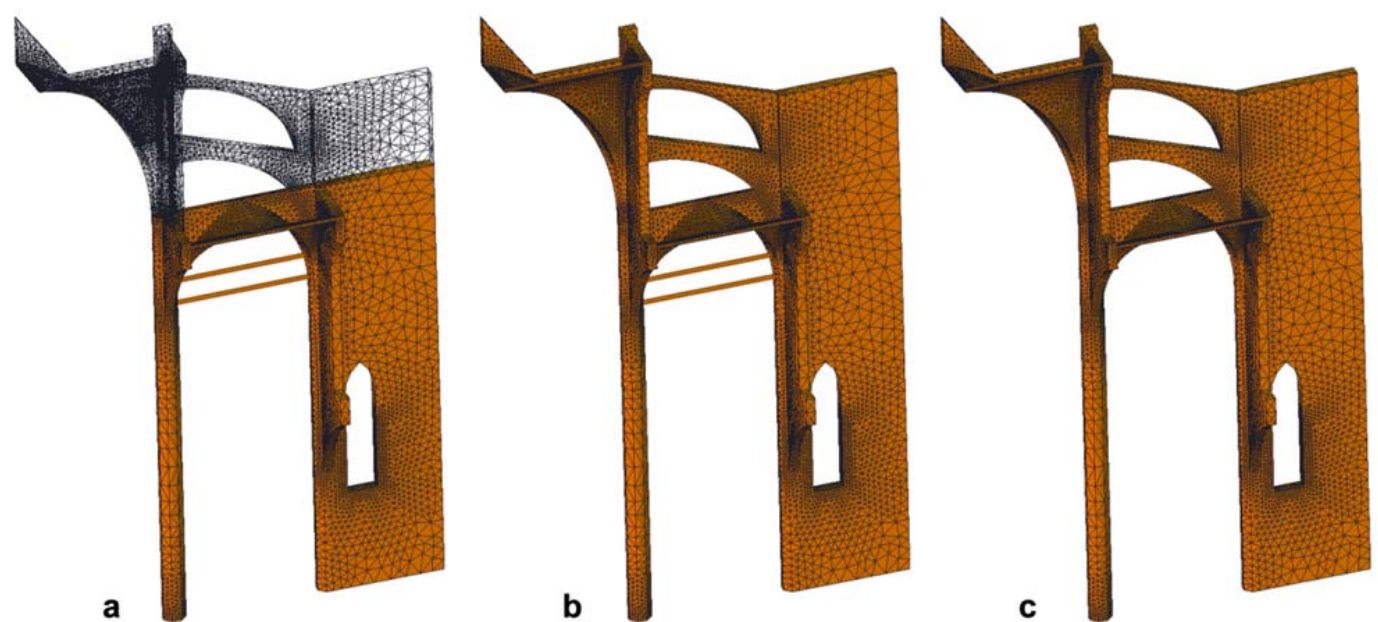

Figure 9 - FE analysis of the construction process: a) first stage (construction of the aisle), b) second stage (completion of the bay) and c) third stage (removal of ties). 


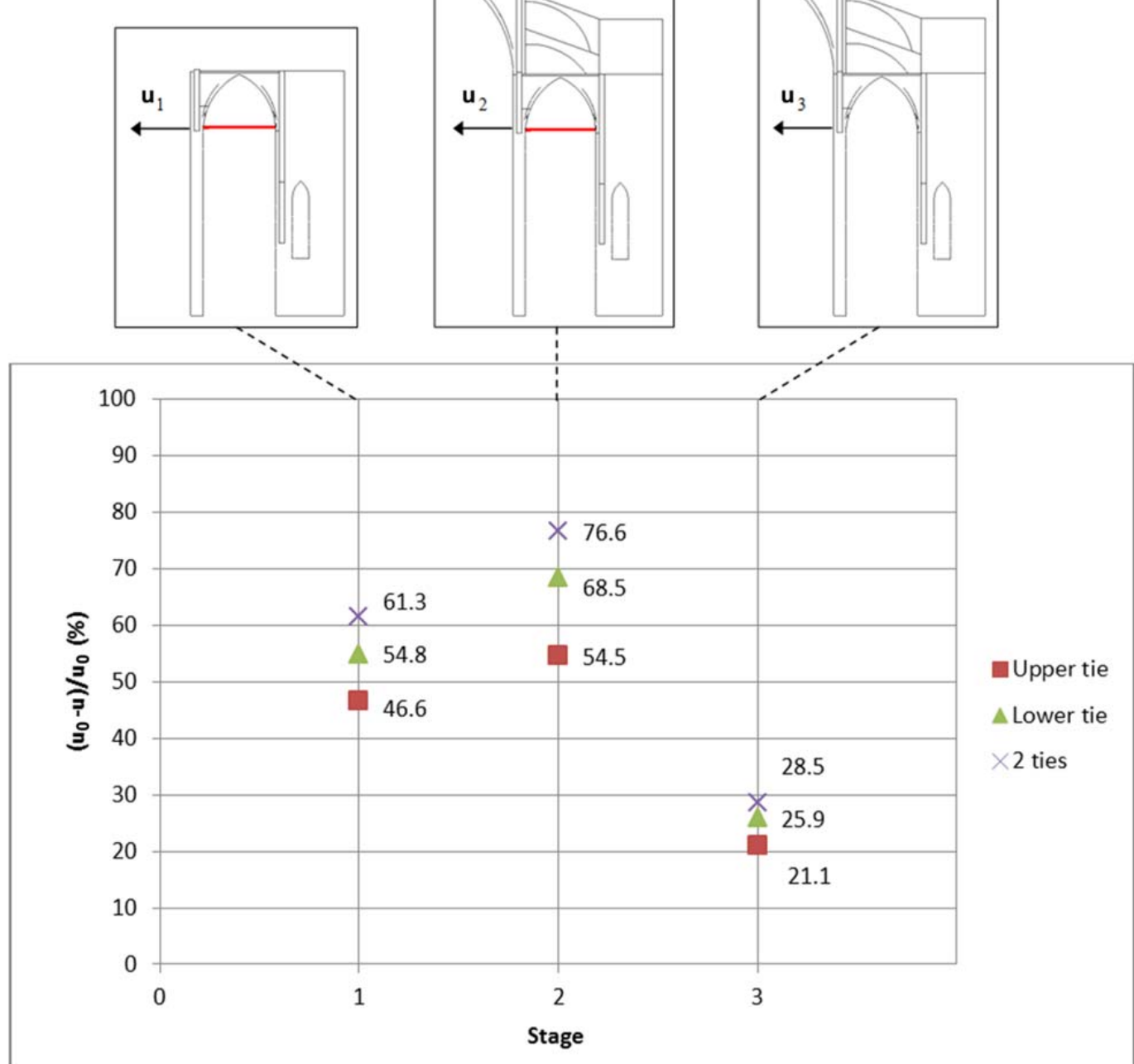

Figure 10 - FE simulation of the construction process: ratio $\left(u_{0}-u\right) / u_{0}$ expressing the restrain effectiveness at each stage for different ties configurations. 


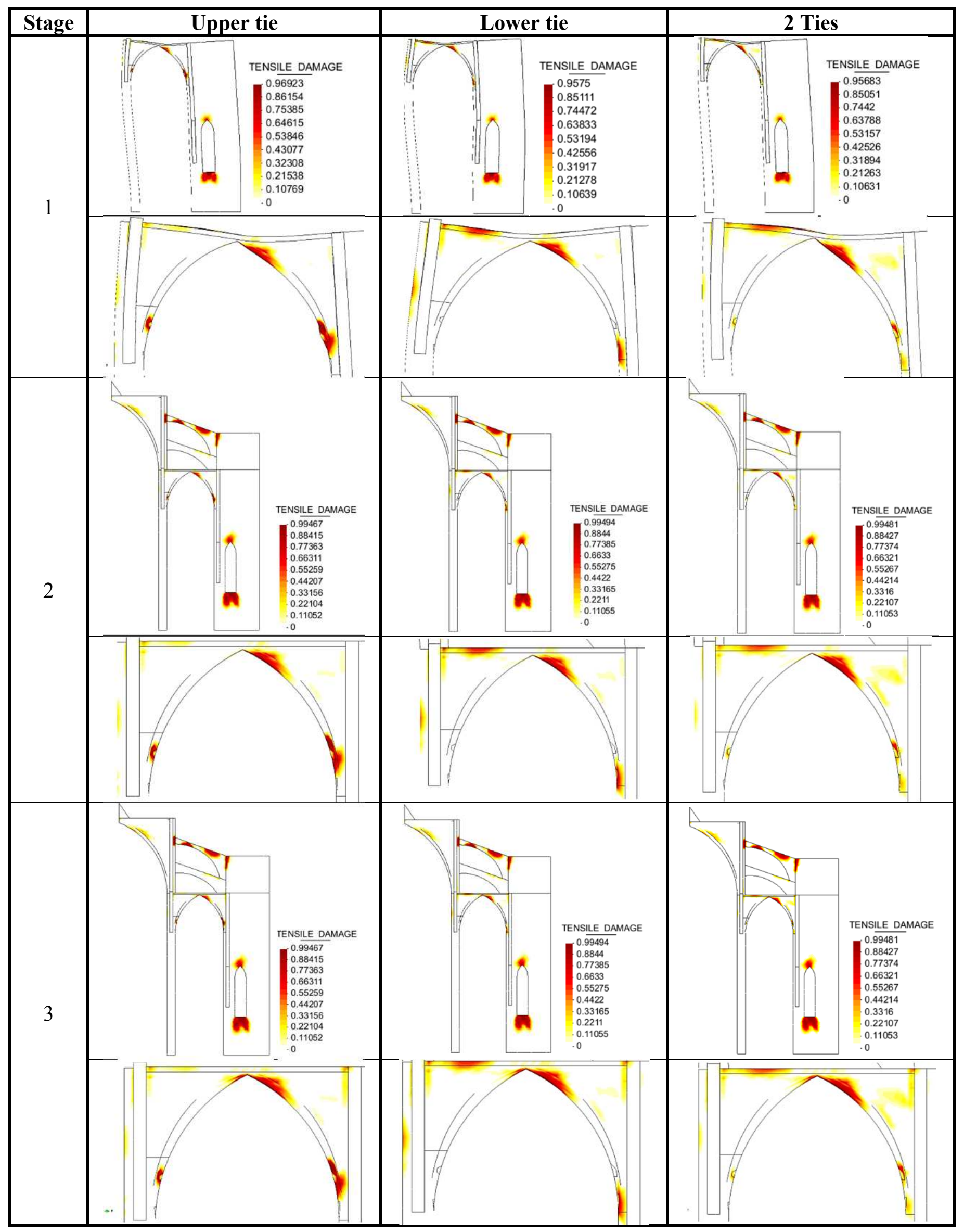


Figure 11 - FE simulation of the construction process: tensile damage contour at each stage for the three different ties configurations.

a
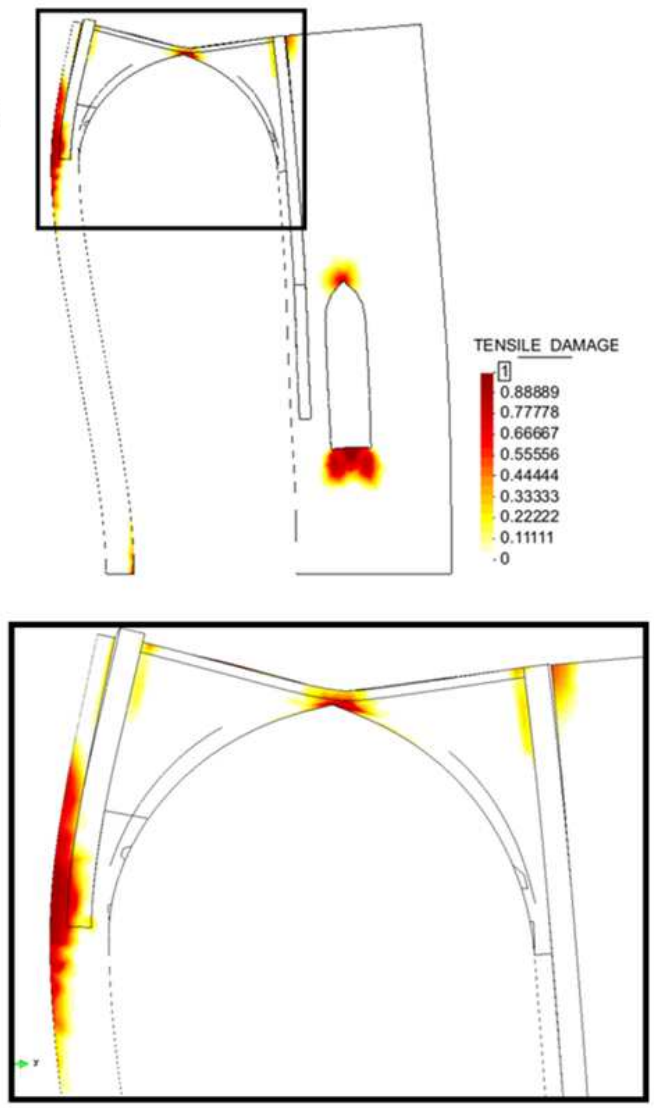

b
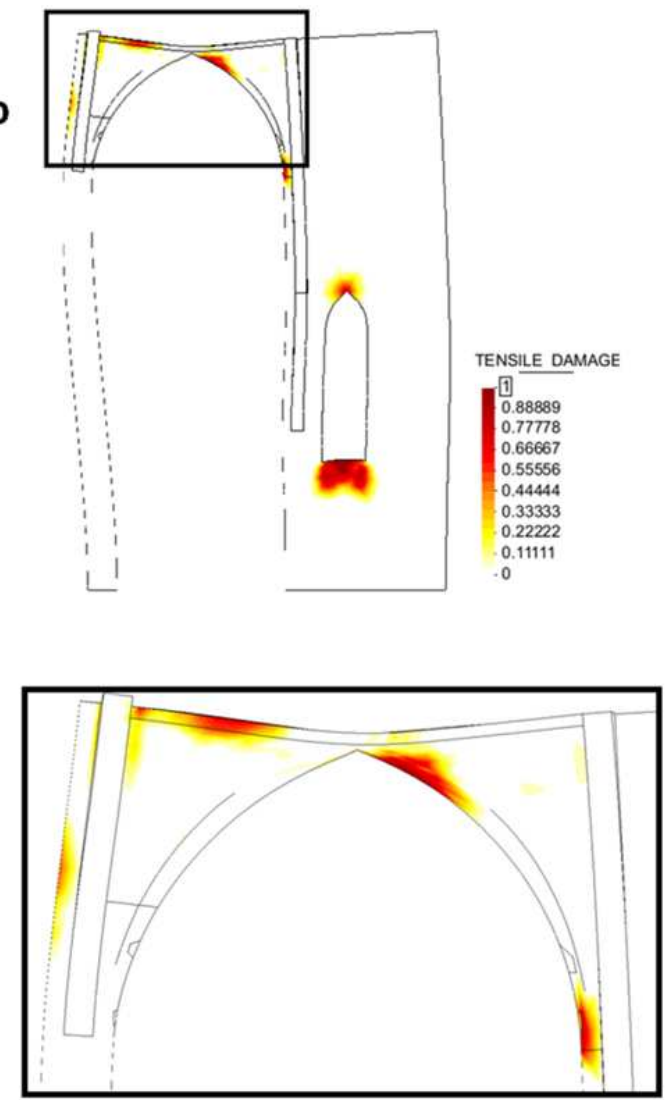

Figure 12 - FE simulation of the construction process: comparison of the tensile damage contour and the deformed shape (x100) at the end of the first stage for the configuration without tie (a) and for the lower-tie configuration (b). 


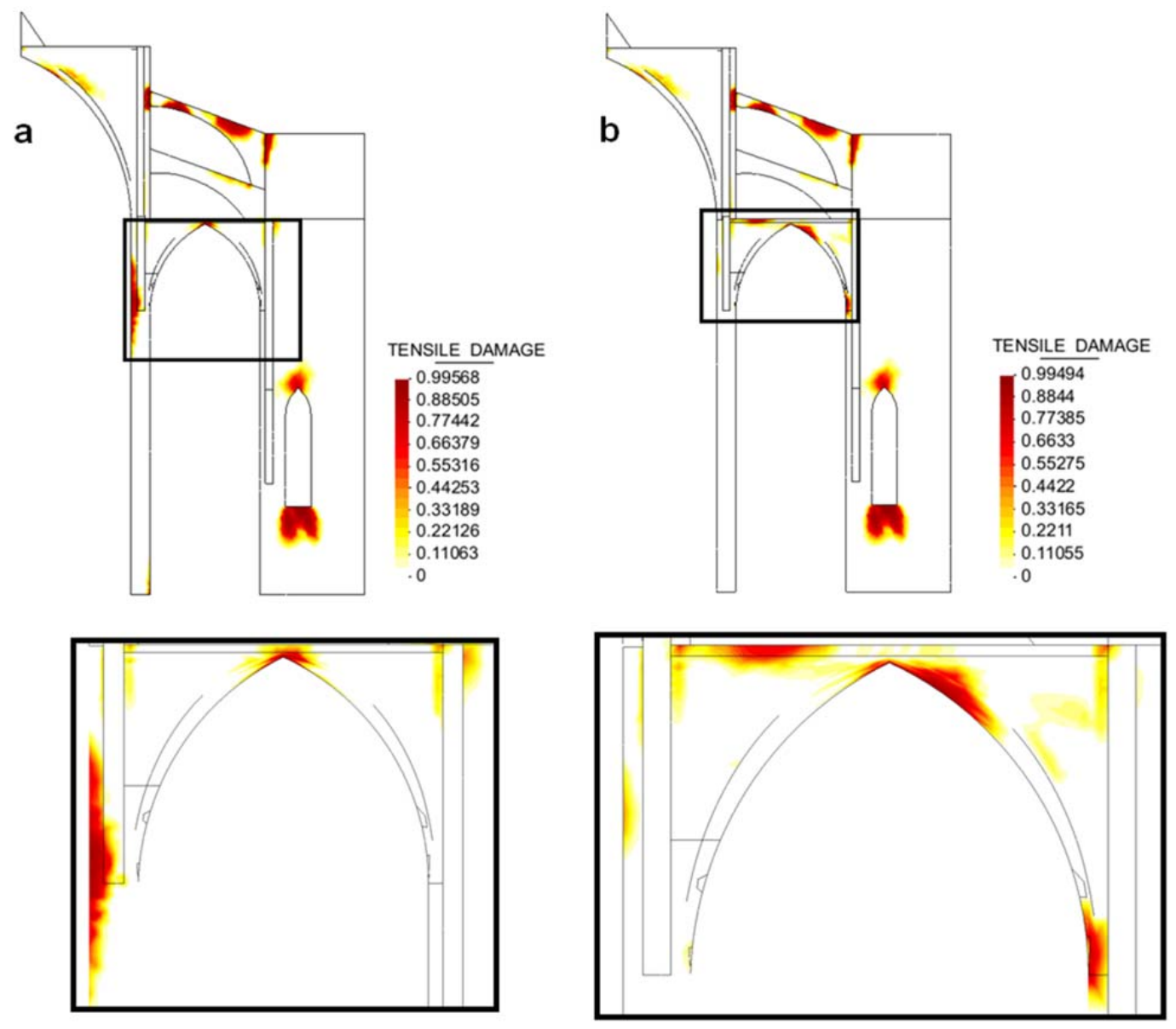

Figure 13 - FE simulation of the construction process: comparison of the tensile damage contour at the end of the third stage for the configuration without tie (a) and for the lower-tie configuration (b). 

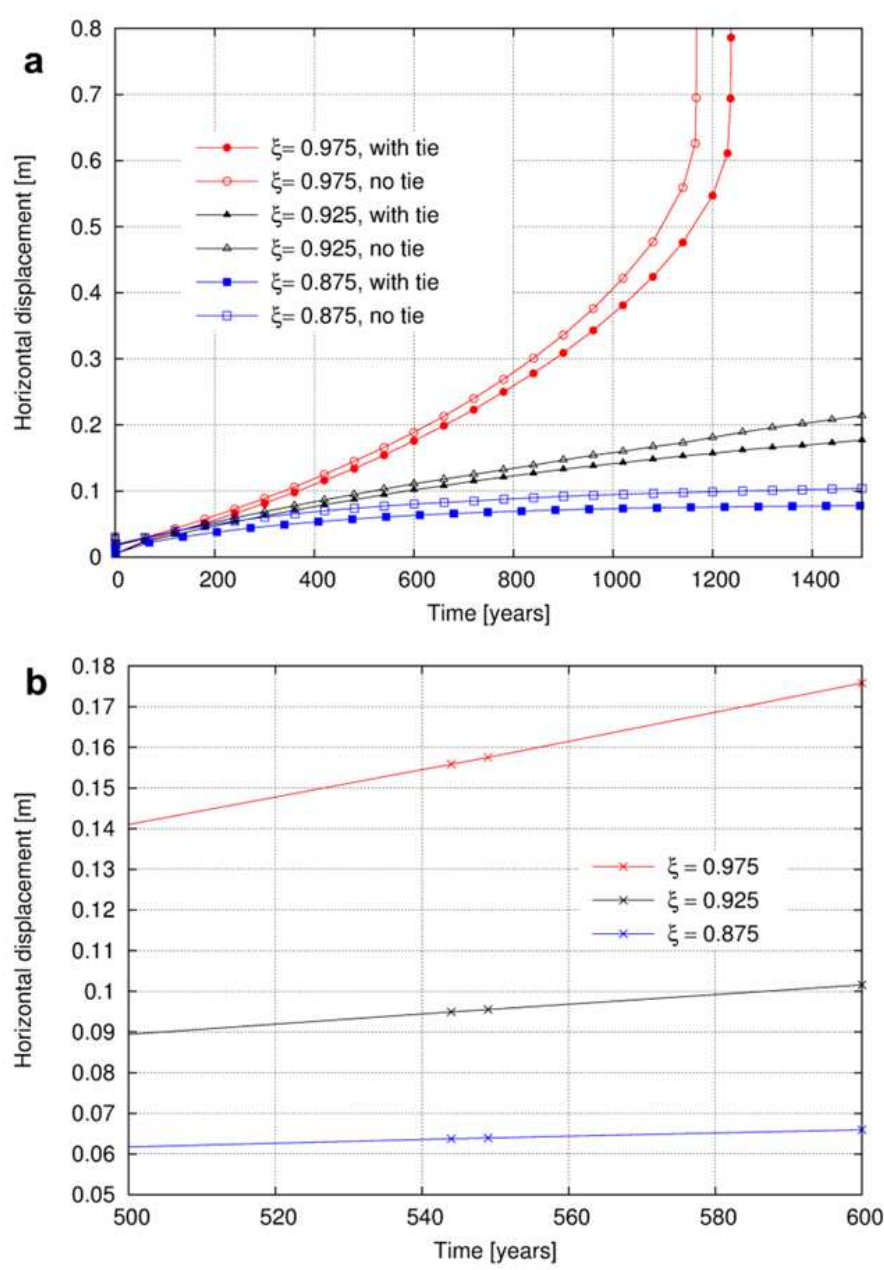

Figure 14 - FE simulation of long-term deformation: horizontal displacements increase at the top of the pier due to creep for a lower tie configuration and a configuration without tie (a), zoom of the curves on the neighbourhood of the monitoring period for the lower tie configuration (b). 

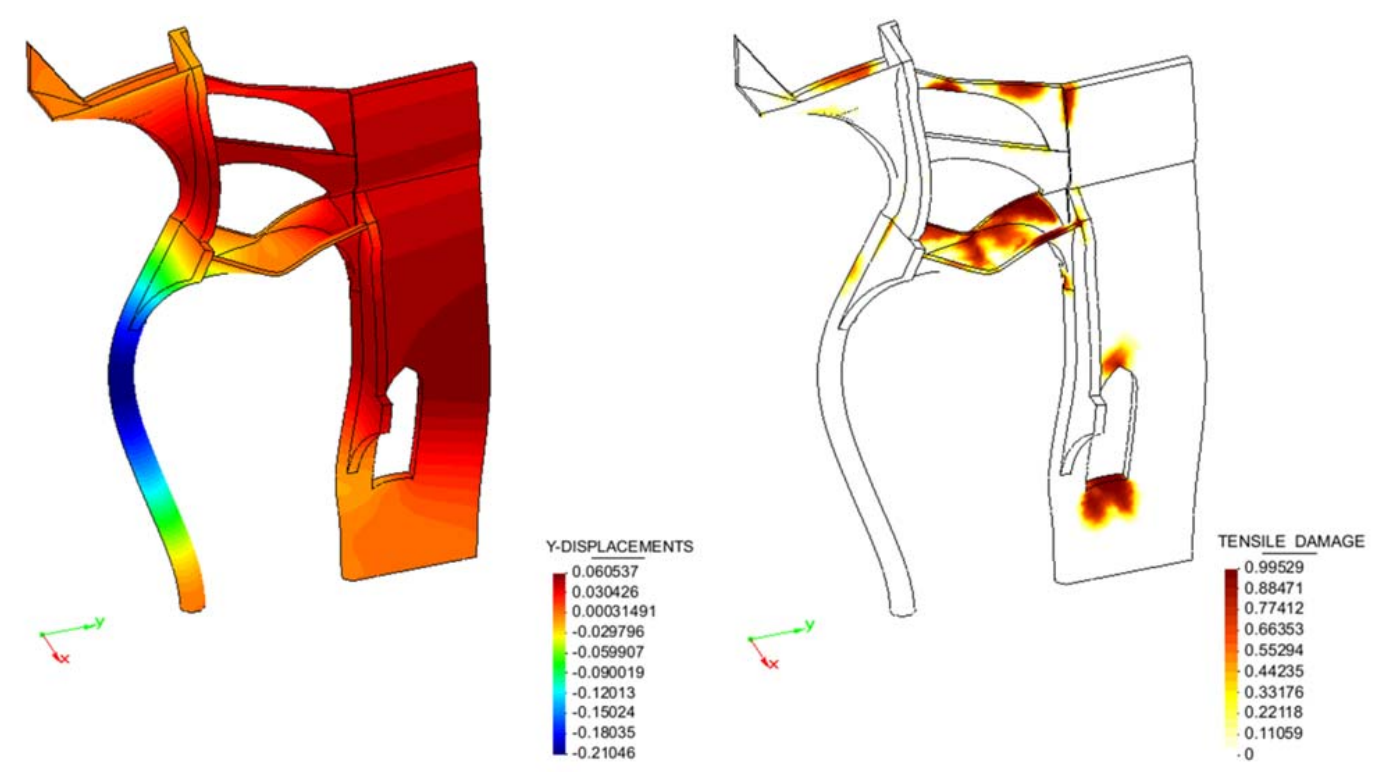

Figure 15 - FE simulation of long-term deformation in the 4th bay with a lower tie: deformed shape (x20) with horizontal displacement contour (left) and tensile damage (right) for $\xi=0.925$.

Table 1 - Materials properties implemented in the FE model.

\begin{tabular}{|c|c|c|c|c|c|c|}
\hline Model & Structural Element & $\begin{array}{c}\boldsymbol{V} \\
(\mathbf{k g} / \mathbf{m} 3)\end{array}$ & $\begin{array}{c}\mathbf{E} \\
(\mathbf{M P a})\end{array}$ & $\mathbf{v}(-)$ & $\begin{array}{c}\mathbf{f t} \\
(\mathbf{M P a})\end{array}$ & $\begin{array}{c}\mathbf{f c} \\
(\mathbf{M P a})\end{array}$ \\
\hline \multirow{2}{*}{$\begin{array}{c}\text { Tension compression } \\
\text { damage }\end{array}$} & Flying arches, piers & 2400 & 8000 & 0.2 & 0.40 & 8.00 \\
\cline { 2 - 7 } & $\begin{array}{c}\text { Clerestory, buttresses, } \\
\text { vaults, ribs }\end{array}$ & 2100 & 2000 & 0.2 & 0.10 & 2.00 \\
\cline { 2 - 7 } & Central vault backing & 2000 & 1000 & 0.2 & 0.05 & 1.00 \\
\hline Elastic & Iron ties & 7874 & $2 \cdot 10^{5}$ & 0.278 & - & - \\
\hline
\end{tabular}

Table 2 - Horizontal displacements at the top of the pier after each stage of the FE simulation of the construction process for different ties configurations.

\begin{tabular}{|c|c|c|c|c|}
\hline Stage & No tie & Upper tie & Lower tie & 2 ties \\
\hline $\mathbf{1}$ & $0.030 \mathrm{~m}$ & $0.016 \mathrm{~m}$ & $0.014 \mathrm{~m}$ & $0.012 \mathrm{~m}$ \\
\hline $\mathbf{2}$ & $0.017 \mathrm{~m}$ & $0.008 \mathrm{~m}$ & $0.005 \mathrm{~m}$ & $0.004 \mathrm{~m}$ \\
\hline $\mathbf{3}$ & $0.017 \mathrm{~m}$ & $0.014 \mathrm{~m}$ & $0.013 \mathrm{~m}$ & $0.012 \mathrm{~m}$ \\
\hline
\end{tabular}


Table 3 - Tensile forces and stresses after each stage of the FE simulation of the construction process for different ties configurations.

\begin{tabular}{|c|c|c|c|}
\hline Stage & Configuration & $\mathbf{F}_{\mathbf{t}} \mathbf{( k N )}$ & $\sigma_{\mathbf{t}} \mathbf{( M P a )}$ \\
\hline \multirow{4}{*}{$\mathbf{1}$} & Upper tie & 119.3 & 95.4 \\
\cline { 2 - 4 } & Lower tie & 121.5 & 97.2 \\
\cline { 2 - 4 } & $\begin{array}{c}\text { Two ties } \\
\text { (upper/lower) }\end{array}$ & $70.4 / 83.3$ & $56.3 / 66.7$ \\
\hline \multirow{4}{*}{2} & Upper tie & 96.3 & 77.1 \\
\cline { 2 - 4 } & Lower tie & 98.6 & 78.9 \\
\cline { 2 - 4 } & $\begin{array}{c}\text { Two ties } \\
\text { (upper/lower) }\end{array}$ & $50.7 / 70.9$ & $40.6 / 56.7$ \\
\hline
\end{tabular}

